\title{
Finance and Efficiency: Do Bank Branching Regulations Matter?*
}

\author{
Viral V. Acharya \\ London Business School, \\ NYU-Stern \\ \& $C E P R$ \\ vacharya@stern.nyu.edu
}

\author{
Jean Imbs \\ HEC Lausanne, \\ Swiss Finance Institute \\ \&) CEPR \\ jimbs@unil.ch
}

\author{
Jason Sturgess \\ Georgetown University \\ jds224@georgetown.edu \\ dia
}

First draft: September, 2006 This Draft: 3 April 2009

\begin{abstract}
We document that the deregulation of bank branching restrictions in the United States triggered a reallocation across sectors, with end effects on state-level volatility. This change in state-level volatility cannot be explained simply by shifts in sector-level returns and volatility. A reallocation effect is at play. To study this effect, we invoke a benchmark allocation based on mean-variance portfolio theory applied to sectoral returns. We find that the realized sectoral allocation of output at the state-level converges towards this benchmark allocation, at a rate that is hastened following the deregulation. This partly occurs because sectors with zero weight in the benchmark allocation see their share of total output shrink. We show convergence is particularly strong in sectors characterized by young, small and external finance dependent firms, and for states that have a larger share of such sectors. The findings are robust to the endogeneity of deregulation dates. They suggest that improving bank access to branching affects the sectoral specialization (or diversification) of output, in a manner that depends on the variance-covariance properties of sectoral returns, rather than on their average only.
\end{abstract}

Key words: Financial development, Growth, Volatility, Diversification, Deregulation, Liberalization, Mean-variance efficiency.

JEL classification: E44, F02, F36, O16, G11, G21, G28

*We thank Phil Strahan for sharing with us a variety of data on banking deregulation for the United States,
and for his comments on the paper. We are also grateful to F. Boissay (EFA discussant), Giovanni Dell'ariccia,
Denis Gromb, Raghuram Rajan, Antoinette Schoar, David Thesmar and seminar participants at Bank of
England, Bank for International Settlements (BIS), CREI (Pompeu Fabra), EFA Meetings (2007), Ente
Einaudi, Indian School of Business, IMF, London Business School, Corporate Finance Workshop at London
School of Economics, Princeton University, Stockholm School of Economics, Trinity College Dublin, Uni-
versitat van Amsterdam (UVA), University of Lausanne, University of Southampton, University of Toronto,
Conference on Financial Modernization and Economic Growth in Europe (Berlin) and the World Bank. Fi-
nancial support from the Research and Materials Development (RAMD) grant from London Business School
and the National Center of Competence in Research (NCCR) "Financial Valuation and Risk Management" is
gratefully acknowledged. NCCR is a research instrument of the Swiss National Science Foundation. Parts of
this paper were written while Imbs was visiting the Institute for International Integration Studies at Trinity
College Dublin, and while Imbs and Acharya were visiting the International Monetary Fund (IMF). The
hospitality of these institutions is gratefully acknowledged. A part of this paper was completed while Viral
Acharya was full-time at London Business School. The usual disclaimer applies.

Contact author: Viral Acharya, Contact: Department of Finance, Stern School of Business, New York University, 44 West 4 St., Room 9-84, New York, NY - 10012, US. Tel: +1 212998 0354, Fax: +1 212995 4256, e-mail: vacharya@stern.nyu.edu. 


\title{
Finance and Efficiency: \\ Do Bank Branching Regulations Matter?*
}

\begin{abstract}
We document that the deregulation of bank branching restrictions in the United States triggered a reallocation across sectors, with end effects on state-level volatility. This change in state-level volatility cannot be explained simply by shifts in sector-level returns and volatility. A reallocation effect is at play. To study this effect, we invoke a benchmark allocation based on mean-variance portfolio theory applied to sectoral returns. We find that the realized sectoral allocation of output at the state-level converges towards this benchmark allocation, at a rate that is hastened following the deregulation. This partly occurs because sectors with zero weight in the benchmark allocation see their share of total output shrink. We show convergence is particularly strong in sectors characterized by young, small and external finance dependent firms, and for states that have a larger share of such sectors. The findings are robust to the endogeneity of deregulation dates. They suggest that improving bank access to branching affects the sectoral specialization (or diversification) of output, in a manner that depends on the variance-covariance properties of sectoral returns, rather than on their average only.
\end{abstract}

Key words: Financial development, Growth, Volatility, Diversification, Deregulation, Liberalization, Mean-variance efficiency.

JEL classification: E44, F02, F36, O16, G11, G21, G28 


\section{Introduction}

Over the past decade, an extensive literature in international finance has confirmed the role of financial development as an important catalyst for growth and allocative efficiency. The catalytic effects of financial development can arise through two channels, not necessarily mutually exclusive: First, there could be an improvement in the levels of growth (or the volatility) of individual sectors in the economy, as in Rajan and Zingales (1998). Second, there could be reallocation effects, i.e. an improvement in the allocation of capital across sectors given unchanged growth rates, as in Wurgler (2000). Our goal in this paper is to investigate the link between financial development and reallocation effects, focusing on the precise nature of specialization (or diversification) of output in the real economy. In particular, we study the effect of deregulation in bank-branching restrictions in the United States (US) on the allocation of output across sectors in US states. In the process, we provide a methodology inspired by mean-variance portfolio analysis to measure and benchmark such reallocation effects.

We use data on Gross State Product (GSP) from the Bureau of Economic Analysis (BEA) from 1977 to 2000. ${ }^{1}$ We approximate the return for a sector (state) by the growth rate of output in that sector (state). Table 1 crystallizes the empirical importance of reallocation effects. We follow the approach in Jayaratne and Strahan (1996) and investigate shifts in growth and volatility around the years when bank branching restrictions were lifted for different states. At the state-level, growth rates increase on average as in Jayaratne and Strahan (1996), and their volatility falls as in Morgan, Rime and Strahan (2004). Interestingly, when estimated at the disaggregated, sectoral level, the same specification yields different results. Growth rates continue to increase but the effect is only half the magnitude of the state-level effect. Volatility, in turn, is left largely unchanged. Thus, it must be that pure reallocation effects contribute significantly to explaining aggregate, state-level results, especially as regards the fall in volatility. State-level volatility fals, but industry-level volatility does not.

While the literature has often considered aggregate growth and volatility separately, our focus on reallocation across sectors provides a natural way of analyzing the two effects jointly. To facilitate an econometric analysis of the exact nature of reallocation, we structure our

\footnotetext{
${ }^{1} \mathrm{GSP}$ is the value-added output located in a state and can be considered as the state-level counterpart to the country's Gross Domestic Product (GDP). There are differences however. Unlike GDP, GSP excludes the compensation of federal civilian and military personnel stationed abroad and the government consumption of fixed capital for military structures located abroad and for military equipment (except office equipment). GSP and GDP also have different revision schedules. The original data are disaggregated at the level of 63 sectors, which we aggregate up to 18 and 10 sectors (see Appendix).
} 
approach around a classic model of the diversification motive, which embeds both growth and volatility effects. For each state, we construct a benchmark set of sectoral weights based on the portfolio-theoretic notion of mean-variance efficiency (MVE).

Our choice of MVE for a benchmark specialization is motivated by its economic appeal in explaining optimal portfolio allocation. The use of state-level data, in turn, offers an approximation to the local component of most banks lending decision. We use the time-series of sectoral returns to calculate for each state the expected return and variance-covariance matrix of returns within eighteen (or ten) consolidated sectors. Next, we numerically compute the MVE frontier for each state in the mean return - standard deviation space and identify the resulting tangency portfolio. It is that tangency portfolio that determines each state's benchmark allocation of output across sectors. Then, for each state and at each point of time, we compute the Euclidean distance between the MVE frontier and the effective expected return and volatility for the state, where expected return and volatility fluctuate over time only because of changes in each state's allocation of output across sectors.

We then ask how these distance measures relate to bank branching deregulation dates. To account for the specificity and partial irreversibility of capital, we allow the effect of deregulation to be gradual rather than instantaneous. In particular, we investigate the time-series properties of the gap measures, and whether their convergence is affected by deregulation. We find that the distance to the MVE frontier shrinks significantly faster following deregulation, so that the long-run distance is significantly smaller in deregulated states. Volatility also converges faster towards the MVE benchmark following deregulation. But we do not find a significant effect on the convergence of returns. Put another way, the primary effect of the imposition of branching restrictions appears to have been to limit the diversification the reduction in volatility - of state-level output across sectors. This is consistent with the results in Table 1.

We are fully abstracting from shifts in returns and volatility around deregulation dates. By the same token, our empirics are controlling for these shifts, and identify separately whether reallocation is at play in the data. In other words, we purge our estimates from a phenomenon well documented in the literature: that growth rates are directly affected by bank branching deregulation. We focus instead on pure reallocation effects, i.e. on the difference between state and sector estimates in Table 1. In particular, the fact that we find little evidence of growth-enhancing reallocation does not mean bank branching deregulation does not affect growth performance: It just means that state-level growth increased because 
the returns themselves shifted at the sector level - not because of a reallocation. State-level volatility, in constrast, fell mostly because of a reallocation mechanism.

Observed sectoral shares of output also converge significantly faster towards their benchmark MVE levels after bank branching deregulation. A number of sectors have weights equal to zero according to the MVE allocation. The convergence we document partly relies on the gradual disappearance of these sectors, which are dominated in an MVE sense. That is, these are not necessarily low growth sectors; they can also be high volatility ones and/or highly correlated ones. This illustrates the usefulness of benchmark MVE computations that account for the variance-covariance properties of sectoral returns in each state, relative to an alternative based on growth prospects only.

Why should the allocation of capital at the local level respond to a deregulation in the banking sector? First, deregulation in bank-branching restrictions allows for improved risksharing both within banks and in the wider economy. Banks predominantly invest in small and private firms with risk-return characteristics not reflected in the stock market or public debt market. ${ }^{2}$ The presence of state-specific bank-branching regulation can therefore limit risk-sharing at the state level. In addition, the response of production should occur at a local level, as it is well known banks predominantly invest locally. We use state-level information to capture this local dimension. ${ }^{3}$

We investigate the channels through which convergence toward the benchmark allocation occurs following deregulation. We examine which sectors and which states display a larger response. In the spirit of Rajan and Zingales (1998), we find that convergence is significantly faster for sectors that are characterized by young and small firms (more likely to be financially constrained and dependent on bank finance), and that rely on external finance. Sectors with younger and smaller firms have higher average growth and higher volatility. They also have

\footnotetext{
${ }^{2}$ Demirguc-Kunt and Levine (2001), for instance, present data showing that bank loans in the United States contributed approximately $50 \%$ of total corporate financing through the 1990's, and that, on average, $85 \%$ of bank financing was to private firms.

${ }^{3}$ Local bias in bank lending has been empirically well-documented. Petersen and Rajan (2002), show that, although the median distance of bank lending increased though the 1970-90s, it was as small as 5.0 miles in 1990-93. Further, whilst the proportion of unit (single branch) banks has fallen, it remained significant even after deregulation, and so local diversification is the only strategy for many banks. In 1977, 8,373 (58\%) from a total 14,411 banks were unit banks. In 2000 the number had reduced to 2,528 (30\%) unit banks from a total of 8,315 banks. More broadly, the empirical literature in finance has asked whether information frictions can explain home bias in shareholder portfolios (see French and Poterba (1991) and Lewis (1999)). Coval and Moskowitz $(1999,2001)$ have documented that professional investment managers also exhibit a strong preference for locally headquartered firms, particularly small, highly levered firms that produce non-traded goods.
} 
output shares that are significantly below their benchmark MVE levels at the beginning of our sample, but not at the end. These sectors contribute increasingly to overall state output following banking deregulation. The findings are reminiscent of Acemoglu and Zilibotti (1997) who argue theoretically that investments in high risk, high return technologies may be attained only after sufficiently high levels of diversification have been reached.

In a similar vein, we find that the states experiencing fastest convergence following deregulation are ones where there is a significantly greater share of sectors populated by young and small firms. Interestingly, they also tend to be large states, where the geographical and informational distance between firms and banks is likely to be greater on average, and, in turn, diversification gains to banks from branching deregulation are likely to be higher as well.

It is conceivable that branching deregulation could arise because of an exogenous need to move away from a given pattern of allocation across sectors, for instance because of technological change. Then, financial deregulation and reallocation would both occur because of unobserved developments, and our estimates would be biased. If these unobserved developments are economy-wide, then the bias should prevail equally in sectors populated by young or old, small or large firms, and irrespective of a technological need for external finance. Our evidence on differential effects between firms that seem constrained and others alleviates these endogeneity concerns to some extent. We also explicitly demonstrate that the branching deregulation dates are not related to the likely benefits of deregulation, measured, for example, by the initial distance of a state's allocation from the benchmark MVE frontier.

Finally, even after branching deregulation is completed, the dynamics of out-of-state bank capital continue to hasten convergence. This finding suggests that access to greater finance through interstate banking flows is essential in order to realize fully the economic benefits of branching. In fact we show the crucial outcome of branching deregulation that affects sectoral allocation of output appears to be the emergence of larger, better-diversified and healthier banks, rather than simply an increase in the number of banks or branches operating in a state.

Our approach is predicated on the stationarity of sectoral output growth rates and volatility, outside of the effects of deregulation. We show the time series of returns are stationary around deregulation dates and that our results are robust to non-stationarity. Specifically, we implement tests of non-stationarity across all sectors and all states. We conclude that sectoral output returns, and their second moments, are stationary outside of the deregulation 
shock itself. We are careful that our specification actually controls for these one-off shifts, so that they do not affect our conclusions on pure reallocation effects. In addition, we perform stationarity tests sector by sector, and repeat our estimation on a sub-sample formed by sectors where non-stationarity is rejected with 0.1 percent confidence. Our results continue to obtain.

Overall, our findings imply that financial development has important consequences for the specialization of output in a manner that depends directly on the variance-covariance properties of sectoral returns, as implied by the literature on mean-variance efficiency. The paper's contribution is also methodological. The simple notion of mean-variance efficiency based on a trade-off between risk and return has been argued to have limitations from a dynamic standpoint, especially in the context of financial investments. The notion nevertheless stands useful in a positive sense. Even if one does not consider the MVE frontier to be the optimal one, observed allocations seem to converge towards it. To show this, we compute the sum of absolute pairwise differences in observed sector shares of output between all distinct pairs of states in our sample. This discrepancy reflects the evolution of differences in the state-level allocation of output. We show that there is a permanent discrepancy between state-level allocations, but that this is well explained by differences in the benchmark specialization patterns, given by each state's MVE frontier. In other words, the frontier serves as an attractive tool for understanding the direction in which the output patterns of US states evolve over time.

In robustness checks, we rule out several alternative hypotheses. We show that our results hold for the subset of states for which we can compute a "clean" MVE frontier, constructed using data exclusively posterior to the deregulation date. We show that there is no convergence towards alternative benchmark allocations. The allocation of output does not converge to a naive frontier ascribing equal weights to all sectors, or computed on the basis of growth prospects only, i.e. with zero covariance terms. These results suggest the convergence properties we document are not mechanical. We do not merely find reallocation towards high growth sectors; how much they co-vary with other sectors is crucial. The exclusion of stable sectors (Government, Health and Education) and of a directly affected sector (Finance, Insurance and Real Estate) does not affect the results either. Finally, the convergence results are also insensitive to the choice of an interest rate for computing the tangency portfolio of the MVE frontier, or to the use of a GMM estimator. For the sake of brevity, we detail these results in a companion document available upon request.

The rest of the paper is organized as follows. Section 2 discusses the related literature. 
Section 3 presents our econometric methodology and data. Section 4 presents the results on te convergence properties of output allocation and Section 5 investigates the channels through which banking deregulation affects this convergence. Section 6 presents a discussion of robustness tests and related issues. Section 7 concludes.

\section{Related literature}

The notion that financial development should affect growth directly is decades old. King and Levine (1993) and Levine and Zervos (1996) established the empirical link at the aggregate level, while Beck, Levine and Loayza (2000) decompose the effect into the responses of total factor productivity and capital accumulation. In disaggregated data, Rajan and Zingales (1998) show that financial development affects growth more for those sectors that tend to rely on external finance for technological reasons. Beck et al. (2008) extend this work to find that financial development also eases constraints within sectors that are more dependent on small firms. Fisman and Love (2004) provide evidence on a finance-growth nexus on the basis of co-movements in growth rates of countries at similar levels of industrial and financial development. Chari and Henry (2002) document that opening financial markets to foreign investment results in greater growth for capital-poor countries.

Using the same set of events as we do, Jayaratne and Strahan (1996) establish a link between the lifting of intrastate bank-branching restrictions and economic growth at the US state-level. Strahan (2003) refines this finding and shows this growth acceleration was particularly pronounced in the entrepreneurial sector. In a recent paper, Huang (2008) questions the robustness of these conclusions and finds that out of the 23 deregulation events that he examines, only five give rise to statistically significant growth accelerations.

Reallocation away from unattractive projects and towards high potential activities figures prominently in the list of proposed explanations for the growth effect. A relatively recent literature has investigated this possibility upfront. Wurgler (2000) shows that well-developed capital markets are conducive of investment efficiency in that they tend to direct investment towards sectors that turn out to grow fast subsequently, and away from declining sectors. Bekaert et al (2007) find financial development has significant reallocation effects towards sectors with high growth potential, as proxied by their stock value. The argument rests on the assumption that subsequent growth is exogenous to the current allocation of capital: financial markets excel at picking sectors with high growth prospects, but expected growth itself is taken as given. 
In more disaggregated data, Black and Strahan (2005) show that new incorporations increased in the US post interstate banking deregulation and more so where the fraction of assets held by large banks was greater. Bertrand, Schoar and Thesmar (2007) study the deregulation of the French banking sector in the mid-1980s and document that in bankdependent sectors, deregulation led to decline in bank credit for worse-performing firms, higher firm-creation and exit rates, and higher market share for better-performing firms.

The majority of these studies have focused - explicitly or implicitly - on growth effects. A few papers have also pointed to changes in volatility, working through - once again explicitly or implicitly - reallocation or diversification mechanisms. For instance, Morgan, Rime and Strahan (2004) show that state-level macroeconomic stability has increased in the US post banking deregulation. Demyanyk, Ostergaard and Sorensen (2007) show that the amount of interstate personal insurance increased following the deregulation of US banking restrictions, and reason this reflects better diversification opportunities. In a cross-section of countries, Larrain (2006) provides evidence that access to bank finance dampens output volatility at the industrial level thanks to countercyclical borrowing by financially constrained sectors. This is a result of better risk pooling and diversification by banks.

Diversification motives are prominent in accounting for lower volatility in these papers. But they are absent from the conventional model of capital allocation, which typically relies on differences across sectors in the marginal return to capital. Then, capital chases higher returns until they are equalized. Our focus on an alternative view where returns are given (or stabilized at a steady state) and where their covariances matter, puts diversification motives back in the front row. It does so in a framework where it is possible to think jointly about the growth and volatility effects of finance, consistent with a vast (but disjoint) literature. One of the few papers going down this route is a study by Raddatz (2006), who analyses both growth and volatility effects at the international level. He shows that sectors with large inventories (assumed to capture liquidity needs) have greater volatility of output growth and lower output growth in underdeveloped financial markets.

\section{Methodology and data}

\subsection{Benchmark mean-variance allocations}

Let $Y_{i, s, t}$ denote nominal output, measured by GSP, for sector $i$ in state $s$ in year $t$. We measure returns $\left\{R_{s, i, t}\right\}$ as the $\log$ output growth rate, $\ln \left(Y_{i, s, t} / Y_{i, s, t-1}\right)$. We estimate $E[R]_{s}$ 
and $\Sigma_{s}$, the vector of expected (average) returns and the variance-covariance matrix of returns on sectors in state $s$. Let $w_{s, i}$ denote the weight of sector $i$ in total output of state $s$. We compute the mean-variance portfolios for state $s$ as the vector of weights $w$ across sectors $i$ obtained from the program

$$
\max _{w \geq 0} w^{\prime} E[R] \text { such that } \sqrt{w^{\prime} \Sigma w} \leq \sigma
$$

for varying values of $\sigma$, the volatility of returns. State indexes are omitted for simplicity.

The mean-variance efficient (MVE) frontier is the set of points $\{(\hat{\mu}(\sigma), \sigma)\}$ in the mean - standard deviation space, where $\hat{\mu}(\sigma)=w^{\prime} E[R]$, the maximized expected return from the above program for volatility $\sigma$. It is well known that the efficient frontier is a hyperbola so we restrict the mapping $\hat{\mu}(\sigma)$ to correspond to the higher of the two possible mean returns for a given volatility $\sigma$. The inverse mapping will be denoted as $\hat{\sigma}(\mu)$.

Realized weights for state $s$ in year $t$ are denoted as $\left\{w_{s, i, t}\right\}$, where $w_{s, i, t}=Y_{s, i, t} / \sum_{i} Y_{s, i, t}$, is the share of sector $i$ 's output in the total gross output of state $s$. The expected return and volatility of state $s$ in year $t$, given the realized weights in year $t$, are denoted as $\mu_{s, t}$ and $\sigma_{s, t}$, respectively, where $\mu_{s, t}=w_{s, t}^{\prime} E[R]_{s}$, and, $\sigma_{s, t}=\sqrt{w_{s, t}^{\prime} \Sigma_{s} w_{s, t}}$, with obvious vector notation.

We define the Euclidean distance to the MVE frontier of state $s$ in year $t$ as

$$
D_{s, t}=\sqrt{\left(\mu_{s, t}-\hat{\mu}\left(\sigma_{s, t}\right)\right)^{2}+\left(\sigma_{s, t}-\hat{\sigma}\left(\mu_{s, t}\right)\right)^{2}} .
$$

In words, from a given point $\left(\mu_{s, t}, \sigma_{s, t}\right)$ in the mean - standard deviation space, we traverse distances moving west and north separately (in a straight line) until the MVE frontier is met. While this definition of distance to the frontier runs throughout the paper, we will also demonstrate robustness of our results to alternatives.

Our first convergence test examines how distance for state $s$ converges to the MVE frontier, and whether deregulation of the banking sector has had any effect on this relationship. We estimate the convergence equation

$$
D_{s, t+1}=\left(\alpha+\beta * D E R E G_{s, t}\right) D_{s, t}+\gamma * D E R E G_{s, t}+\delta_{s}+\theta_{t}+\varepsilon_{s, t},
$$

where $D E R E G_{s, t}$ is a binary variable taking value one if the banking sector in state $s$ has been deregulated by year $t$. We are interested in whether $\beta<0$, that is whether deregulation hastens the convergence towards efficiency. ${ }^{4}$ Since the MVE frontier is estimated with error,

\footnotetext{
${ }^{4} \beta<0$ also implies that distance in the long run is significantly smaller in deregulated states.
} 
there is an attenuating bias in estimates of $\alpha$ and $\beta$. This works against finding a significant effect of deregulation. The inclusion of state and time effects enables us to capture the pure within-state effects of deregulation. We also allow for clustered standard errors by state.

We next define a tangency portfolio on the MVE frontier. For a constant risk-free rate $r$, we can define a benchmark MVE allocation of output for each state, corresponding to the tangency point between the frontier and a straight line arising from holding the risk-free asset. ${ }^{5}$ A mean-variance efficient investor with complete access to the risk-free asset and the investment portfolio of the state would choose a risk-return tradeoff along this tangency line. The tangency portfolio for state $s$ is denoted as $\left(\mu_{s}^{*}, \sigma_{s}^{*}\right)$, and the corresponding output shares for each sector $i$ as $\left\{w_{s, i}^{*}\right\}$.

Since our focus is on reallocation, we investigate how the time-varying expected return and volatility for state $s$ and its realized output shares relate to their MVE counterparts return, volatility and weights for the tangency portfolio. In particular, we seek to establish whether the deregulation of the banking sector has affected this relationship.

We estimate

$$
\begin{aligned}
\mu_{s, t+1}-\mu_{s}^{*} & =\left(\alpha+\beta * D E R E G_{s, t}\right)\left(\mu_{s, t}-\mu_{s}^{*}\right)+\gamma * D E R E G_{s, t}+\delta_{s}+\theta_{t}, \\
\sigma_{s, t+1}-\sigma_{s}^{*} & =\left(\alpha+\beta * D E R E G_{s, t}\right)\left(\sigma_{s, t}-\sigma_{s}^{*}\right)+\gamma * D E R E G_{s, t}+\delta_{s}+\theta_{t}, \text { and } \\
w_{s, i, t+1}-w_{s, i}^{*} & =\left(\alpha+\beta * D E R E G_{s, t}\right)\left(w_{s, i, t}-w_{s, i}^{*}\right)+\gamma * D E R E G_{s, t}+\delta_{s, i}+\theta_{t} .
\end{aligned}
$$

As in equation (1), the inclusion of state (or state-by-sector) and time effects helps us isolate the within-state (within-state-by-sector) effect of deregulation. We are again interested in whether estimates of $\beta$ are non-positive. In equations (2) and (3), we test whether deregulation hastens convergence towards efficiency in expected returns and volatilities. Negative estimates for $\beta$ will imply long run state growth and volatility that are closer to their MVE levels. Second, equation (4) verifies whether deregulation induces a reallocation across sectors within a state in the direction implied by the tangency portfolio weights for that state. Negative estimates for $\beta$ will also imply an average vector of long run output shares closer

\footnotetext{
${ }^{5}$ The assumption of a constant risk-free rate is made for simplicity: What matters is that the rate is identical for all the US states, an assumption that is largely uncontroversial. The underlying idea here is similar to that in estimations of the capital asset-pricing model in finance, where mean-variance efficiency is assumed to apply period after period and the risk-free rate taken to be the average return realized on government treasuries for a one-year horizon. For most of the paper, we take the risk-free rate to be simply zero. As a robustness check in a companion paper available upon request, we show that our results are not sensitive to the choice of a specific value for the risk-free rate.
} 
to the MVE allocation. ${ }^{6}$

To summarize, equations (1)-(3) are tests of the convergence of state-level aggregates towards MVE benchmarks, whereas equation (4) is a test of reallocation at the sector-level within a state toward MVE frontier weights. The latter will be the lynch-pin of our analysis in Section 5 where we investigate the channels through which deregulation affects reallocation. In particular, we will examine the characteristics of those sectors and states where reallocation effects are faster in response to financial development.

We assume throughout a stationary covariance matrix of returns. We later verify that the assumption can be maintained in our data. There is however a specific kind of shift in mean returns (or potentially their volatility) documented in the literature, namely the possibility that returns themselves should shift with deregulation. What if returns were indeed systematically higher, or less volatile, post-deregulation? Would assuming this away not create a bias in our estimates? We now detail why our specifications are robust to this possibility. Suppose for instance we do not measure the true benchmark return $\mu_{s}^{*}$, as a result of a violation of our time invariance assumption. In particular, assume the benchmark return we compute, $\tilde{\mu}_{s, t}$, be different from its true value as follows

$$
\tilde{\mu}_{s, t}=\mu_{s}^{*}+\tilde{\gamma}_{1} * D E R E G_{s, t}
$$

where we have allowed for a systematic shift in state returns around the deregulation date, captured by $\tilde{\gamma}_{1}$. This is what Jayaratne and Strahan (1996) find. Consider now the specification in equation (2). It is easy to convince oneself that disregarding a break in returns because of branching deregulations will not affect estimates of $\beta$, since $\tilde{\gamma}_{1}$ is effectively subsumed in estimates of $\gamma$ in equation (2). ${ }^{7}$ This is the sense in which our approach purges direct effects on returns, to focus instead on reallocation effects. It is straightforward to extend the same argument to systematic shifts in volatility around deregulation.

The argument also generalizes to estimates at the sector level. We later split our data according to criteria customarily associated with constrained access to external finance, and find convergence is strongest in constrained sectors and states. It is important to ensure these differential effects are not driven by our assumption of time invariance. Suppose again we do not measure the true benchmark weights, because our time invariance assumption is invalid

\footnotetext{
${ }^{6}$ Since the weights across sectors in a given state add up to one, we drop one sector, Agricultural services, from the estimation of equation (4).

${ }^{7}$ This prevents a clean interpretation of $\gamma$, its sign as well as its magnitude, as a measure of the direct effects of deregulation in our estimations.
} 
along the sectoral dimension. To be precise, assume the benchmark weights we compute, $\tilde{w}_{s, i, t}$, differ from their true benchmark level as follows:

$$
\tilde{w}_{s, i, t}=w_{s, i}^{*}+\tilde{\gamma}_{1} * D E R E G_{s, t}+\tilde{\gamma}_{2} * D E R E G_{s, t} \cdot C O N S T R+\tilde{\delta} \operatorname{CONSTR}
$$

where CONSTR denotes a binary variable used to identify constrained sectors. Our computed benchmark weights may differ from the true MVE weights because returns may be higher (and/or less volatile) after deregulation $\left(\tilde{\gamma}_{1}\right)$, in constrained sectors $(\tilde{\delta})$ or indeed in constrained sectors after deregulations $\left(\tilde{\gamma}_{2}\right)$, as demonstrated in Rajan and Zingales (1998). Consider now the specification in equation (4). Measurement error of the types considered is not going to affect our estimates of interest: $\tilde{\delta}$ will only affect estimates of $\delta_{s, i}$, and $\tilde{\gamma}_{1}$ and $\tilde{\gamma}_{2}$ will only affect estimates of $\gamma$. In other words, our results are robust to shifts in returns around deregulation dates, even if these behave in a systematically different manner across constrained or unconstrained sectors.

\subsection{Data}

Our data on nominal Gross State Product (GSP) for the 50 US states and the District of Columbia come from the Bureau of Economic Analysis (BEA). Output is decomposed into 63 sectors over the period 1977 through 2000. Given the time-series limitation, computing the MVE frontier requires collapsing the number of assets (sectors) in the portfolio. We aggregate the NAICS 63 sectors up to 18 sectors, based on the BEA grouping of two-digit SIC codes, and separately up to 10 sectors, as per the recommended classification in Dyck and Zingales (2004). These aggregated sectors are listed in the Appendix. When aggregating, we omit sectors with negligible output shares, i.e. less than 0.1 percent of GSP.

This level of aggregation is consistent with common practice when estimating MVE frontiers. It does however seem coarse from the standpoint of capturing putative reallocations, for which firm level information may be more helpful. Can we hope to observe output reallocations around deregulation dates across 10 or 18 such coarsely defined economic activities? Can we hope for the observed characteristics of these sectors to matter measurably in the process of reallocation? We view these questions as largely empirical. We note however that, if anything, the coarseness of our data makes it relatively more difficult to find significant effects.

The deregulation dates, and the measures of out of state capital in the banking sector are from Morgan, Rime and Strahan (2004). Deregulation of the US banking sector began 
in earnest in the 1970s (see Kroszner and Strahan (1999) and Kroszner (2001) for a detailed description). Until then, the US banking regulation existed at both the intra- and interstate level. Within states, banks were prevented from expanding through either acquisition (of existing banks or branches) or simple branching. Growth was only possible within a multibank holding company (BHC) whereby a bank could acquire existing banks or open new ones but not roll these up into its existing operations. This is likely to have imposed some limitations on diversification possibilities. For instance, capital requirements were imposed separately on each branch, and could not be consolidated.

Under the Douglas Amendment to the 1956 Bank Holding Company Act, a BHC was prohibited from acquiring banks outside the state where it was headquartered, unless the target bank's state permitted such acquisitions. The first state to offer such permission was Maine in 1978 but it was not reciprocated until 1982. This form of reciprocal deregulation offered BHCs the opportunity to acquire banks, but it did not affect interstate branching. Acquirers could not fold newly acquired banking assets into banking operations outside the target's state. By 1994, with the passing of Reigle-Neal Interstate Banking and Branching Efficiency Act, interstate banking was complete, recommended and introduced by all states except Texas and Montana. Before intrastate deregulation a bank holding company (BHC) could expand as a group by buying banks but could not group these into a single bank. Post interstate deregulation (but pre-1994) the same was true between states: banks could move into a new state but not as a single bank.

Table 2 provide some preliminary descriptive statistics of our data. The left panel focuses on state-level statistics, and the right discusses sectoral evidence. We document the characteristics of nominal output growth and volatility at both aggregation levels. Consider first state-level performance. The table suggests average state GSP growth decreased around the deregulation dates, from $8.13 \%$ to $6.92 \%$, which corresponds to the overall macroeconomic cycle in the US. But late adopters of bank branching deregulation (e.g. Wyoming in 1988) grew below that average in the earlier part of the sample, whereas early adopters (e.g. Delaware in 1970) overperformed the US average in the later period. This illustrates the difference in differences approach followed by Jayaratne and Strahan (1996), and their results. Conclusions are similar as regards state volatility: it fell overall, probably a manifestation of what has become known as the "Great Moderation". But early adopters had output volatility below the US average, whereas late adopters had it above.

The right panel of the table examines disaggregated sectoral performance. Average output growth at the sectoral level is virtually identical to state numbers, suggesting that aggregation 
is innocuous on average. The same is not true of volatility measures, because of covariance terms that enter aggregate measures, but not sectoral ones. The table points to substantial heterogeneity in the responses of growth and volatility to deregulation at the sector level. Growth performance fell across the board, but to an extent that differs across sectors. For instance, Agriculture, Farming and Fisheries had the lowest mean growth rate (averaged by sector across states) prior to the deregulation, but it is Mining, Oil, Gas and Non Metallic Minerals that performed worst after the event. This shuffling in the growth experience of different sectors around the deregulation dates is what helps identify the effects we are interested in. The same heterogeneity obtains as regards volatility, where some sectors do actually see their idiosyncratic volatility rise (Health, Educational, Legal, Social and Other Services). Both Agriculture, Farming and Fisheries and Mining, Oil, Gas and Non Metallic Minerals see their volatility decrease around deregulation dates, but by a substantially larger amount in the former sector. Given the observed response in growth rates, this suggests Agriculture, Farming and Fisheries became relatively more attractive, from both a growth and a volatility standpoint.

\section{The effects of banking deregulation on reallocation}

We first examine the convergence of a state towards its MVE frontier in the mean - standarddeviation space of returns (based on the distance measure $D_{s, t}$ ). This does not require taking a stance on the tangency portfolio on the frontier. Next, we investigate the convergence of expected output growth and volatility ( $\mu_{s, t}$ and $\sigma_{s, t}$, respectively) towards their levels at the tangency portfolio ( $\mu_{s}^{*}$ and $\sigma_{s}^{*}$, respectively). Finally, we study the convergence of output shares $\left(w_{s, i, t}\right)$ towards those implied by the tangency portfolio $\left(w_{s, i}^{*}\right)$.

\subsection{Distance to frontier}

Figure 1 provides a simple illustration of convergence for two fast-converging states, Pennsylvania and North Dakota, towards their MVE frontiers. The figure shows that these states converge to their MVE allocations, at an accelerating rate following branching deregulation. We verify such convergence formally in Table 3. We estimate equation (1) for both intraand interstate deregulation. Estimates of the direct auto-regressive coefficient on the Euclidean distance to frontier, $\alpha$, imply a yearly reduction of about $37 \%$ in the distance to the MVE frontier. Importantly, the effect of deregulation interacts negatively with distance as seen from the estimated interaction coefficient $\beta$ in tests using both intrastate and interstate 
deregulation. Thus, deregulation hastens the convergence to the MVE frontier. In terms of magnitude, deregulation accelerates convergence by $10 \%$ per year. The magnitudes are roughly similar across the two levels of aggregation. The point estimates of $\alpha, \beta$ and $\gamma$ for 18 sectors suggest deregulation lowers the long run Euclidian distance to the MVE frontier by a solid $20 \%{ }^{8}$

\subsection{Growth and volatility}

We next investigate whether the movement of states towards the MVE frontier following branching deregulation happens through convergence in state-level growth, its volatility, or both. Both changes would bring a state closer to its frontier, either via leftward movements (involving volatility) or via upward changes (involving growth). Columns two and three in Table 3 provides evidence to answer this question with estimates of equations (2)-(3). We examine the convergence properties of expected output growth $\mu_{s, t}$ (calculated on the basis of realized weights and the expected returns at sector-level) and expected output volatility $\sigma_{s, t}$ (calculated on the basis of realized weights and the variance-covariance matrix of sectorlevel returns). Across both panels (with 18 or 10 sectors), the interaction effect reveals that convergence in volatility towards the MVE benchmark accelerates post deregulation, by about $10 \%$. For 18 sectors, the point estimates imply long run state-level volatility falls by almost 35\%. In contrast, deregulation dates do not affect the convergence of output growth level towards its MVE counterpart: estimates of $\alpha$ are $80 \%$ or higher, but the interaction effect of deregulation is insignificant.

Our results suggest that the primary effect of branching restrictions appears to have been to limit the diversification of activity at the state level. The reallocation of output following branching deregulation has little growth consequence, but induces a substantial diversification effect that manifests itself as lower output volatility. This divergence in results regarding growth or volatility effects is reminiscent of and consistent with our results in Table 1, and suggests reallocation across sectors is at play.

\footnotetext{
${ }^{8}$ We also consider, and find similar results for, alternative measures of distance, which unlike our first definition rely on the specific tangency portfolio for each state, denoted as $\left(\mu_{s}^{*}, \sigma_{s}^{*}\right)$ in Section 3.1. We employ the Euclidian distance to the tangency portfolio computed as

$$
D_{s, t}=\sqrt{\left(\mu_{s, t}-\mu_{s}^{*}\right)^{2}+\left(\sigma_{s, t}-\sigma_{s}^{*}\right)^{2}} .
$$

and the horizontal and the vertical distances to the tangency portfolio, computed as $\left|\sigma_{s, t}-\sigma_{s}^{*}\right|$ and $\left|\mu_{s, t}-\mu_{s}^{*}\right|$, respectively. The convergence results are robust to these alternative measures. Details are available from the authors upon request.
} 
Table 3 also presents the results of estimating equations (1)-(3) using the GMM AranelloBond (1991) estimator, to account for the presence of a lagged dependent variable in dynamic panel data. Our results continue to obtain.

\subsection{Output shares}

We have so far focused on aggregate performance at the state level. To understand the effect of branching deregulation at a disaggregated level, we now investigate the convergence properties of the sector-wise allocation of output around deregulation dates.

In general, our computations suggest there are large differences between realized output shares $w_{s, i, t}$ and the corresponding MVE benchmark weights $w_{s, i}^{*} \cdot{ }^{9}$ In addition, the top five sectors in terms of their MVE weights typically account for between $80 \%$ and $90 \%$ of total output in the state. This structure is not uncommon to estimations of MVE frontiers: stable sectors end up getting most of the weight and the unconstrained estimation generally suggests short-selling some sectors. In our estimation, these get truncated to zero weights by construction. Even for high weight sectors, realized output shares are smaller than the MVE weights by a large factor. A reason for this is that a number of sectors with weights truncated to zero in the estimation of the MVE frontier have realized weights that are greater than zero (even if tiny) and the sum of realized weights across these sectors adds up to being a non-trivial amount.

To address this issue, we make two adjustments. First, we examine whether the zeroweights are important economically by repeating tests for a reduced sample of only those sectors where the MVE weight is non-zero. A problem with including only those sectors whose MVE weights turn out to be non-zero is that the realized weights no longer add up to one for states where at least one sector has a non-zero MVE weight. To normalize for this, we scale the realized weight of each non-zero MVE sector by the sum of realized weights of all such sectors within the state. This adjustment brings the scale of the realized and MVE weights more in line with each other. The resulting non-zero weights represent the allocation in only those sectors where MVE allocation is positive, and ignore all sectors the MVE results suggest should disappear. Estimation of convergence for the resulting weights is reported in the tables under the "Non Zero Weights" heading. In results that follow, we report convergence properties where we retain all sectors (without any adjustment) but also where we focus only on adjusted non-zero weight sectors as described above.

\footnotetext{
${ }^{9}$ Appendix 2 presents the MVE benchmark weights and realized weights, both pre and post deregulation, for a sample of fast-, median-, and slow-converging states.
} 
The second adjustment we undertake is to eliminate the two most stable sectors in our data, as determined by their implied MVE weights, namely Government, and Health and Education. These also tend to be heavily regulated activities. ${ }^{10}$ In our robustness analysis, available as a companion paper, we report that even with complete exclusion of these two sectors from our analysis, conclusions are largely unchanged.

In Table 4, we report the convergence properties of realized output shares, $w_{s, i, t}$, based on equation (4). In the first column, we report results when all sectoral weights are employed without any scaling. The effect of deregulation, as estimated by the "Interaction" coefficient $\beta$, is to hasten convergence of realized weights towards the MVE benchmark. In particular, the convergence rate increases by about 0.6 to $0.8 \%$ per year. The magnitude is small relative to the estimates of convergence coefficients in Table 3, for state-level aggregate measures. But these point estimates capture the average convergence rate of a representative sector $i$ in state s. In Table 4, for instance, they suggest the distance between the long run output share of a representative sector and its MVE counterpart shrinks by approximately $5 \%$ because of deregulation. This may seem a small number, but the effects have to be compounded over 18 sectors. ${ }^{11}$ The corresponding end effects on state-level variables are potentially sizeable, as documented in Table 3.

The second column in Table 4 reports results when only sectors with non-zero MVE weights are included. In this case, the interaction effect is weaker and with 10-sector aggreation, it disappears altogether. This suggests that the complementary set of sectors that have zero MVE weights is crucial to convergence. The number of such sectors is not small for most states and their exclusion clouds inference on convergence of sectoral allocations.

Taken together, Table 4 implies that part of the effect of deregulation is a re-composition of output away from those sectors that have zero MVE weights. This could happen because these sectors correspond to activities that are dominated in the mean-variance space, based on their risk-return tradeoff. Or because these are activities that the mean-variance optimization implies should be shorted, which translates into zero MVE weights. Presumably therefore, zero MVE weights are not merely an artefact of the procedure computing the MVE frontier: they contain relevant information regarding the disappearance of certain sectors in the state. In fact, we found that the average rate of disappearance of such sectors, measured as the

\footnotetext{
${ }^{10}$ When we employ the 10-sector aggregation, the sectors which dominate the MVE weights are Manufacturing (SIC codes 20-39), Finance, insurance and real estate (60-67), Services (70-89), and Government.

${ }^{11}$ For instance, we checked the estimated shift in the convergence of weights around deregulation can explain more than half of the estimated shift in the convergence of volatility at the state-level.
} 
average annual percentage change in their sectoral weights, is $1.03 \%$ in deregulated stateyears, against only $0.21 \%$ in non-deregulated state-years.

The magnitude of these convergence effects is best gauged using specific episodes that happened around deregulation dates. Consider for instance North Dakota, where intrastate deregulation happened in 1987. In un-tabulated results, we find that the change in output weights for North Dakota around the deregulation year is almost perfectly predicted by the ratio of MVE weights to initial weights (with an $R^{2}$ of over $80 \%$ ). The sectoral allocation of output in North Dakota altered almost exactly in the way predicted by mean-variance portfolio theory around the year of deregulation. For instance, Lumber and Wood doubled its weight in the state's economy, a sector whose MVE weight is twenty times its actual pre-deregulation weight. In contrast, Retail fell by a fifth, and its MVE weight is half of its pre-deregulation weight. Interestingly, between 1977 and 2000 the contribution of sectors with zero MVE weights to North Dakota's output also fell by $10 \%$.

Similarly, Illinois deregulated intrastate branching in 1988, and saw the share of Food and Paper fall by a quarter (its MVE weight is half the initial weight in 1977), Transport fell by $20 \%$ (it should fall by half according to its MVE weight), and Leisure and Business Services increased by $15 \%$ (its MVE weight is $150 \%$ of its initial level).

\section{The nature of reallocation}

We have established a strong relation between state-level banking deregulation and state-level reallocation in output shares across sectors. Did the deregulation of branching restrictions for banks cause this reallocation? To answer this important question, we examine the channels through which deregulation affects changes in sectoral allocations. As we explain below, this helps allay concerns of reverse causality, based on the possibility that deregulation happened precisely in states that were expected to have sharp reallocations (for example in anticipation of exogenous technology shocks).

\subsection{Which sectors converge faster?}

We appeal to the methodology of Rajan and Zingales (1998) who study the effect of financial development on sectoral growth in an international setting. They conclude that financial development helps disproportionately more those sectors which are heavily dependent on external finance. Dependence on external finance or the inability to support investments 
through internal cash flows is (at least partly) attributable to sectoral-level technological factors such as payback periods and fixed costs of investment. Using data on capital expenditures and external finance issuance, Rajan and Zingales (1998) calculate explicit measures of external financial dependence. They also employ implicit measures, such as the age and size of firms. These imply informationally opaque activities, which may preclude easy access to capital markets and make them more reliant on bank finance.

Rajan and Zingales (1998) document the significance of an interaction term between financial development (a country characteristic) and external dependence (a sectoral characteristic common across countries) in explaining sectoral growth. The interaction effect helps put at ease the issue of endogeneity of financial development to anticipated growth. If expected technology shocks were the reason why financial deregulation became of the essence (perhaps to accommodate future growth), it is hard to think of reasons why these shocks would disproportionately concern sectors with an exogenous, given need for external finance, or ones that tend to be populated by young or small firms.

Our investigation of the channel through which bank branching deregulation affects the allocation of output across sectors is in the same spirit. If branching restrictions limit the access of banks to the entire spectrum of activities within a state, then the limitation is likely to be felt most severely by those sectors which are most dependent on external finance. If the limitation arises because of information frictions, then sectors with young and small firms may be restricted from obtaining bank financing and also suffer relative to activities populated by more mature or larger firms. Thus, the relaxation of branching restrictions should increase the output shares of these sectors.

This leaves open the following question: where does the capital allocated to financially constrained activities come from? It is possible that banks are able to raise more capital following financial deregulation (since they can become more diversified). It is also possible that they become more efficient, for instance, because increased competition improves the pricing of loans, as documented in Jayaratne and Strahan (1998). ${ }^{12}$ Finally, it is possible that the pool of capital remains unchanged with deregulation, in which case any reallocation would be purely due to transfers of capital away from unconstrained sectors to constrained ones. In all these cases, however, allocations will favor activities that need it most, where we should therefore see faster convergence. Convergence in unconstrained sectors may still

\footnotetext{
${ }^{12}$ In particular, Jayaratne and Strahan (1998) report that non-interest costs, wages and loan losses all fell after states deregulated branching, which resulted in lower prices on loans.
} 
happen, but not necessarily. That depends partly on whether there is overall expansion of capital in the state or merely transfers across sectors. In other words, convergence should be clear in constrained sectors, but not in unconstrained ones.

We split our sample according to a variety of external dependence measures, and estimate equation (4) separately for all sub-samples. We use four measures of external dependence for each sector, computed using the COMPUSTAT dataset for all firms in that sector over the period 1994 to 2005. ${ }^{13}$ We compute: (i) Age, measured as the average age of firms in the sector; (ii) Dependence, defined and measured following Rajan and Zingales (1998), as the ratio of net external finance issues (sale of common and preference stock and debt minus purchase of common and preference stock and debt) to capital expenditures; (iii) Sales, a proxy for firm size measured by the average sales of firms in the sector; and, (iv) Assets, another proxy for firm size, measured by the book value of firm assets. Based on these four measures, we partition our sectors into below- and above-median samples, and label them Young and Old, Unconstrained and Constrained, Small and Large, and Low and High, respectively.

In Table 5A, we report the convergence properties of sectoral shares of output based on these four sample splits. We find that the acceleration of convergence to MVE weights is most pronounced for Young, Constrained, Small and Low Assets sectors. There, the coefficient $\beta$ is negative, significant and at least two to three times larger compared to the complementary samples. The discrepancy is significant at conventional confidence levels in most cases.

To further illuminate the mechanisms at work, we ask whether Young, Constrained, Small and Low Assets sectors have initial allocations that are significantly below their MVE weights, but final allocations that cannot be distinguished from MVE weights. In Table 5B, we present probit estimates of the probability that initial and final weights be below their MVE level, $\operatorname{Pr}\left(w_{i, s, T}<w_{i, s}^{*}\right)$, as a function of the median values for Age, Dependence, Sales and Assets for sector $i$. $T$ equals 1977 for initial weights and 2000 for final weights. Note that since any non-zero realized weight is mechanically greater than a zero MVE weight, we are forced in this analysis to restrict attention to sectors with non-zero MVE weights. The results

\footnotetext{
${ }^{13}$ We choose to measure the external dependence variables over the period 1994 to 2005 , since we wish to measure external dependence over a period when the claim of fully-developed capital markets is tenable within the US. This is akin to Rajan and Zingales (1998), who measure this variable in the US for the 1970s and 80s, and run their test over the 90s. For this period post 1994, all the states had fully deregulated their banking markets and deregulation was complete with the passage of the Interstate Banking and Branching Efficiency Act of 1994. Furthermore, about half of the measurement period 1994 to 2005 is outside of our estimation period 1977 to 2000 .
} 
are striking. The sample splits always matter significantly for the initial level of realized allocation: in 1977, the probability of a sector being below its MVE size is significantly decreasing in Age, (the inverse of) Dependence, Sales and Assets. In contrast, in 2000 these sector characteristics are not as relevant. In particular, Age, Sales and Assets have become insignificant in explaining the probability of allocation being lower than the MVE one (though Dependence has not).

Taken together, these results suggest that banking deregulation in the US produced a reallocation across sectors by primarily increasing the output share of younger, smaller and more external finance dependent firms.

Acemoglu and Zilibotti (1997) argue that investments in high risk, high return sectors may not be attractive unless a critical level of diversification is reached. A direct implication is that risky sectors should contribute more to overall growth once diversification is possible. In Table $5 \mathrm{C}$, we regress the average of realized returns $R_{s, i, t}$ and their time-series volatility on binary variables capturing whether sector $i$ is populated by Old, Unconstrained, Large and High Assets firms. In all cases, returns are lower for old, unconstrained and large sectors, by around 1\%. Volatility is lower for Large and High Assets sectors but surprisingly higher for Old and Unconstrained sectors. Combined with the evidence in Table 5B, we conclude that the fraction of state's output that is generated by sectors with both high returns and high volatility is likely to increase following bank branching deregulation. This effect is consistent with banks having better access to diversification post-deregulation, and as a result, lending to riskier sectors as proposed by Acemoglu and Zilibotti. In terms of economic magnitudes, the cross-state average share of GSP contributed by Young, Dependent, Small and Low Assets sectors had 1977 values of 51\%, 40\%, 52\%, and 43\%, respectively. By 2000, these shares had grown to $60 \%, 44 \%, 60 \%$, and $48 \%$, respectively. These sectors, which on average grow faster by $1 \%$ a year, have thus become more important to US State, by 10 to $15 \%$.

\subsection{Which states converge faster?}

Finally, we examine the characteristics of states that converge faster post-deregulation. We split states according to three criteria. In Table 6, we report estimates corresponding to equation (1) for Euclidean distance to the frontier (Panel A), and to equation (4) for sectoral weights in output (Panel B). We first consider a simple variant of the sector splits employed in the previous section. Specifically, we divide states into two groups based on above and below median values of state-level firm age, calculated as an output-weighted average of sector-level 
(average) firm age for the state in 1977. The results are consistent with those for sector splits. States with a greater share of output in sectors that are populated by younger firms converge significantly faster post-deregulation. Estimates of $\beta$ for these states are negative, significant, and two to four times as large as that for the complementary set of states.

We do not report state-level splits for the other measures employed in Section 5.1, as the results are quite similar. Instead, we bring in alternative data available at the state-level for the US. In particular, in a recent paper Demyanyk, Ostergaard and Sorensen (2007) employ firm-level data on the number of employees, from the Geospatial and Statistical Data Center, maintained at the University of Virginia library. ${ }^{14}$ Using these data, we calculate Firm Size as the 1977 share of firms with fewer than 20 employees in overall state employment. We then split states into samples around the median values of Firm Size. Panels A and B of Table 6 reveal that states that are populated by many small firms have negative and significant values of $\beta$, at least two to three times larger than in states with relatively fewer small firms. Remarkably, the discrepancy is always significantly relevant at conventional confidence levels.

These results are consistent with a stronger effect of banking deregulation in states with younger and smaller firms, likely to be more reliant on bank financing. Finally, we exploit the idea that bank branching restrictions are less likely to have bite in those states that are small. There, we conjecture, the information frictions that prevent a bank from lending to the entire spectrum of borrowers in the state are less important. We split states around the US median value of state geographical area. We expect that the convergence effect of deregulation should be significantly stronger for larger states. The estimates in Table 6 confirm the conjecture.

\section{Stationarity and Robustness}

\subsection{Stationarity}

The stationarity of returns is important for our purposes for two reasons. First, our estimates of a convergence effect rely on the assumption that returns are stationary outside of a potential shift created by the deregulation. Second, our frontier estimates build upon the empirical variance-covariance matrix of growth rates, inclusive of observations before and after the deregulation. We want to make sure our results are not altered if we use matrix

\footnotetext{
${ }^{14}$ They also document that small businesses are important to the economy: In the average state, they find that businesses with less than 100 employees made up $58 \%$ of total employment in 1978.
} 
estimates that exclude the deregulation episode, and focus instead on a "clean" liberalized episode. We now address both concerns.

An assumption we maintain throughout is that returns display no further non-stationarity, both in terms of their mean and their volatility, beyond the structural breaks documented in Tables 1 and 2. The assumption of stationarity in sectoral growth rates underpins a large literature in international macroeconomics. Stockman (1988), Costello (1993), Forni and Reichlin (1988), and Koren and Tenreyro (2007) all assume a stationary structure of shocks. Kose et al (2003) use Bayesian techniques to assess whether the relative importance of different components has changed over time.

In what follows, we perform tests of non-stationarity in returns to investigate the validity of this assumption. Panel A in Table 7 presents the results of the panel unit-root test introduced by Im, Pesaran and Shin (2003), performed on sectoral data. The null hypothesis maintains that all series in the panel be non-stationary, as against the alternative that some are not. We purge the data used in the estimation from the effect of bank deregulation, using the residuals of a regression on a binary variable taking value one after the event in each state. The question is whether non-stationary behavior subsists in these residuals. Table 7 paints a clear picture. In virtually all cases, we overwhelmingly reject the null hypothesis that returns, or their volatility, are non-stationary. Since there are no trends specified in the specifications of Table 7, this also rejects the hypothesis that returns or their volatility be trend-stationary. We interpret this evidence as supportive of our assumption that sectoral returns, and their second moments, are stationary - once a structural break around the deregfulation is accounted for.

In Panel B of Table 7 we report additional evidence that putative non-stationarity is not driving our results. We select sectors for which we can strongly reject the null hypothesis of non-stationarity in the Levin, Lin and Chu (2002) unit-root test, where rejection occurs at the 0.1 percent confidence level or less. For these sectors we repeat the tests reported in Table 4 for convergence in weights. These new tests are reported in Table 7B. We find that our convergence results are unaffected. In similar, unreported, estimations we show that our results on reallocation channels continue to obtain for the selected strongly stationary sectors. On the basis of these tests we conclude that non-stationarity is not driving our results.

We compute MVE frontiers using data on sectoral returns pre- as well as post-deregulation dates. In Table 8, we demonstrate empirically that this concern does not seem to create a bias in our estimations. We compute a clean MVE frontier using post-deregulation data only. 
We restrict attention to those 16 states that deregulated their branching restrictions early enough in our sample to give us at least 12 years of data post-deregulation. For these states, we compute an uncontaminated frontier for 10 aggregated sectors, and repeat the estimation of equations (1)-(4). As in Tables 5 and 6, deregulation hastens convergence towards the MVE frontier through a volatility effect, but not through a growth effect. As before, sectoral shares of output converge to their benchmark values faster following deregulation, but only when we include sectors with zero benchmark weights. The magnitude of the coefficient estimates is also roughly similar.

Such robustness is important, for it confirms that the convergence results we obtain throughout the paper are not an artefact of the frontier itself effectively responding to deregulation. Even if state-level frontiers do shift in response to deregulation, we still find evidence of convergence induced by the deregulation episode.

\subsection{Robustness}

We conduct an extensive robustness analysis, whose detailed exposition is left for a companion paper available upon request for the sake of brevity. We first investigate whether convergence exists towards alternative benchmark allocations. We compute the frontier implied by a variance-covariance matrix that uses the empirical variances, but where all covariances are set to zero. This illustrates the importance of (positive or negative) co-movements in sectoral growth rates, for the computation of benchmark allocations. We also use a naive allocation where all sectors have identical size. In both cases, we find no convergence, and no effect of deregulation. This is reassuring, because it suggests our convergence results are not mechanical, and are driven by the joint distribution of sectoral growth rates.

Next, we exclude exceptionally stable sectors (Government, Health and Education), or the Finance, Insurance and Real Estate sector. We continue to obtain our results. We also use alternative values for the risk free rate to compute efficient weights, again with no observable effect on our conclusions. We use the GMM estimator introduced by Blundell and Bond (1998), again without effects. We verify deregulation dates are not endogenous to the nature of reallocatio, which we measure using our frontier metric. There is essentially no relation between the distance to MVE frontier and the timing of the deregulation.

Our measure of financial deregulation is a binary variable, by definition unable to capture how much the lifting of branching restrictions favored reallocation. An attractive alternative is introduced in Morgan, Rime and Strahan (2004), who compute the total out-of-state assets 
held by holding companies operating in state $s$ in year $t$, divided by total assets in state $s$. This provides a continuous variable, capturing the magnitude of the flows in banking capital across states. We use this measure instead of $D E R E G_{s, t}$ in equations (1) and (4). We find the same results, even though the data is effectively restricted to those state-years where interstate regulations were lifted - since otherwise there can be no out-of-state capital.

Finally, we illustrate that it is the emergence of larger, better-diversified and healthier banks following branching deregulation that leads to reallocation, rather than a simple, mechanical change in the market structure of the banking sector. We run a horse-race between out-of-state capital and the Herfindahl-Hirschman index of bank concentration in the state, with weights in the index implied by the deposit base of each bank. We find that the effect of out-of-state capital is robust to controls for bank concentration in the state. In fact bank concentration by itself (after controlling for flows) impedes convergence. Replacing the Herfindahl index by the number of banks or branches in the state produces similar results. This continues to be true when we control for the health of banks operating in a state. We approximate this with the average state capital to assets ratio, i.e., the total capital of banks operating in the state divided by their total assets. Again, we find the convergence effect in response to deregulation. In this case however, the health of the banking sector also contributes to the effect.

\section{Discussion and Concluding Remarks}

We use the concept of static mean-variance efficiency to structure our analysis of the dynamics of specialization in output. In its conventional applications, pertaining to the allocation of capital across financial assets, static mean-variance efficiency is rapidly losing its appeal. In a positive sense, we find it interesting that it should help understand the allocation of real output. It fits naturally with, and in fact brings together, the largely disjoint segments of the literature on the growth and volatility effects of access to finance. As we now show, the concept also contributes to explaining the unconditional evolution of patterns of sectoral output in the US states, that is, even outside of the deregulation effects.

We compute a measure of the bilateral (dis-)similarity in the allocation of output between states. We calculate the sum of absolute distances between realized output allocations at a given point of time: For a pair of states $s$ and $u$, define $\operatorname{Gap}_{t}=\sum_{i}\left|w_{s, i, t}-w_{u, i, t}\right|$. In Table 9, we examine the convergence properties of $G_{a p}$ in an auto-regressive specification. In Column 1, we allow for year effects and state-pair fixed effects, whereas in Columns 2 and 3, we only 
have year effects. In Column 1, we show the dis-similarities of output allocation across states have a permanent component, as testified by the significant intercept. This continues to be the case in Column 2, where country-pair specific intercepts are omitted. Even in the long run, patterns of output are different across states, and do not converge towards a vector of common, national, output shares.

What is the source of these permanent discrepancies in the sectoral allocations of output across states? An answer is provided in Column 3 where we compute $G_{a} p_{t}^{*}=G a p_{t}-\sum_{i} \mid w_{s, i}^{*}-$ $w_{u, i}^{*}$, which controls for the cross-state discrepancies in benchmark MVE allocations. Note that by construction, the MVE allocation is time-invariant and thus so is the measure Gap . Column 3 shows that the intercept ceases to be significant once permanent differences in MVE allocations are accounted for. In other words, the long run differences in observed output shares across states are well explained by the gap in the benchmark allocations implied by the MVE frontier estimated state by state. $^{15}$

In short, mean-variance efficiency appears to be an empirically plausible candidate to explain the long run properties of output allocation in US states. We have shown that convergence to the MVE benchmark is accelerated by financial development, with focus on the deregulation of bank-branching restrictions. This acceleration seems to correspond to an improved diversification of output, translating in lower volatility rather than faster growth. Since our approach concentrates on pure reallocation effects, this is not saying that growth has not responded. Indeed it has, but not via reallocation effects.

Our conclusions are strongest in sectors that are populated by young, small and financially constrained firms, and they are indeed often absent from the complementary samples. They are also strongest in states that are populated by high numbers of small and young firms, and, interestingly, in large states. These differential effects highlight the exact nature of reallocation induced by financial development, and indirectly signify the importance of banks for small, young, financially constrained firms as well as the local (even if gradually diminishing) component of expertise in bank lending.

Finally, our contribution is methodological in nature. With a large ongoing interest in quantifying the real effects of financial integration, and in particular a mounting body of ev-

\footnotetext{
${ }^{15}$ Can one explain the cross-section of these very state-specific benchmark allocations, i.e. the intercept in column 3 of Table 9? The pattern of output specialization across states does presumably also respond to fundamentally different forces than those discussed in our paper. The distribution of factor endowments, natural resources or comparative advantage come to mind, and are likely to be of the essence. These are far from the characteristics we have been focusing on in our within-state analysis. We leave the investigation for future research.
} 
idence supportive of real effects on economic growth, our mean-variance approach unbundles some of the mechanisms at play. We are able to pinpoint whether finance induces reallocation through diversification of output or simply produces higher output. We are further able to characterize the very nature of finance-induced specialization: which activities and sectors benefit, which do not, and why. The richness of our methodology may thus be useful in a variety of contexts, for instance for analyzing the causes, nature and effects of international financial flows. 
Appendix 1: Industry Classification

\begin{tabular}{|c|c|c|}
\hline $\begin{array}{l}63 \text { Sector SIC } \\
\text { Classification }\end{array}$ & $\begin{array}{c}18 \text { Sector } \\
\text { BEA Classification }\end{array}$ & $\begin{array}{c}10 \text { Sector } \\
\text { Dyck-Zingales Classification }\end{array}$ \\
\hline Agriculture, Farming \& Fisheries & 1 & 1 \\
\hline Agric. Services & 2 & 1 \\
\hline Metal Mining & 3 & 2 \\
\hline Coal mining & 3 & 2 \\
\hline Oil \& Gas & 3 & 2 \\
\hline Nonmetalic Minerals & 3 & 2 \\
\hline Construction & 4 & 3 \\
\hline Lumber \& Wood & 5 & 4 \\
\hline Furniture \& Fixtures & 5 & 4 \\
\hline Stone, Clay, \& Glass & 6 & 4 \\
\hline Primary Metals & 6 & 4 \\
\hline Fabricated Metals & 6 & 4 \\
\hline Industrial Machinery & 6 & 4 \\
\hline Electronic Equipment & 6 & 4 \\
\hline Motor Vehicles & 6 & 4 \\
\hline Other Transport Equipment & 6 & 4 \\
\hline Instruments \& related & 6 & 4 \\
\hline Miscellaneous Manufacturing & 6 & 4 \\
\hline Food \& kindred products & 7 & 4 \\
\hline Tobacco products & 7 & 4 \\
\hline Textile Mill products & 7 & 4 \\
\hline Apparel \& Textile & 7 & 4 \\
\hline Leather products & 7 & 4 \\
\hline Paper products & 7 & 4 \\
\hline Printing \& Publishing & 7 & 4 \\
\hline Chemicals & 7 & 4 \\
\hline Petroleum products & 7 & 4 \\
\hline Rubber \& Plastics & 8 & 4 \\
\hline Leather products & 8 & 4 \\
\hline Railroad Transportation & 9 & 5 \\
\hline Trucking \& Warehousing & 9 & 5 \\
\hline Water Transportation & 9 & 5 \\
\hline Transportation by Air & 9 & 5 \\
\hline Pipelines, excluding Natural Gas & 9 & 5 \\
\hline Transportation Services & 9 & 5 \\
\hline Communications & 10 & 5 \\
\hline Electric, Gas, \& Sanitary & 11 & 5 \\
\hline Wholesale trade & 12 & 6 \\
\hline Retail trade & 13 & 7 \\
\hline Depository Institutions & 14 & 8 \\
\hline Nondepository Institutions & 14 & 8 \\
\hline Security Brokers & 14 & 8 \\
\hline Insurance Carriers & 14 & 8 \\
\hline Insurance Agents & 14 & 8 \\
\hline Real Estate & 14 & 8 \\
\hline Holdings \& Investments & 14 & 8 \\
\hline Hotels \& Lodging & 15 & 9 \\
\hline Personal services & 15 & 9 \\
\hline Business services & 15 & 9 \\
\hline Auto repair \& Parking & 15 & 9 \\
\hline Miscellaneous repair services & 15 & 9 \\
\hline Motion Pictures & 15 & 9 \\
\hline Amusement \& Recreation & 15 & 9 \\
\hline Health services & 16 & 9 \\
\hline Legal services & 16 & 9 \\
\hline Educational services & 16 & 9 \\
\hline Social services & 16 & 9 \\
\hline Other services & 16 & 9 \\
\hline Membership Organizations & 16 & 9 \\
\hline Private Households & 16 & 9 \\
\hline Business services \& Other services & 17 & 9 \\
\hline Government & 18 & 10 \\
\hline
\end{tabular}

Notes: The left hand column describes the 63 SIC industrial sectors (omitting "Unclassified" which is excluded from both the 18 and 10 sector classifications), the middle column describes the 18 BEA industrial sectors and the right hand column describes the 10 industry classification as described by Dyck-Zingales. The 18 industrial sector classification is used for the main results and the 10 industrial sector classification is included for robustness. 


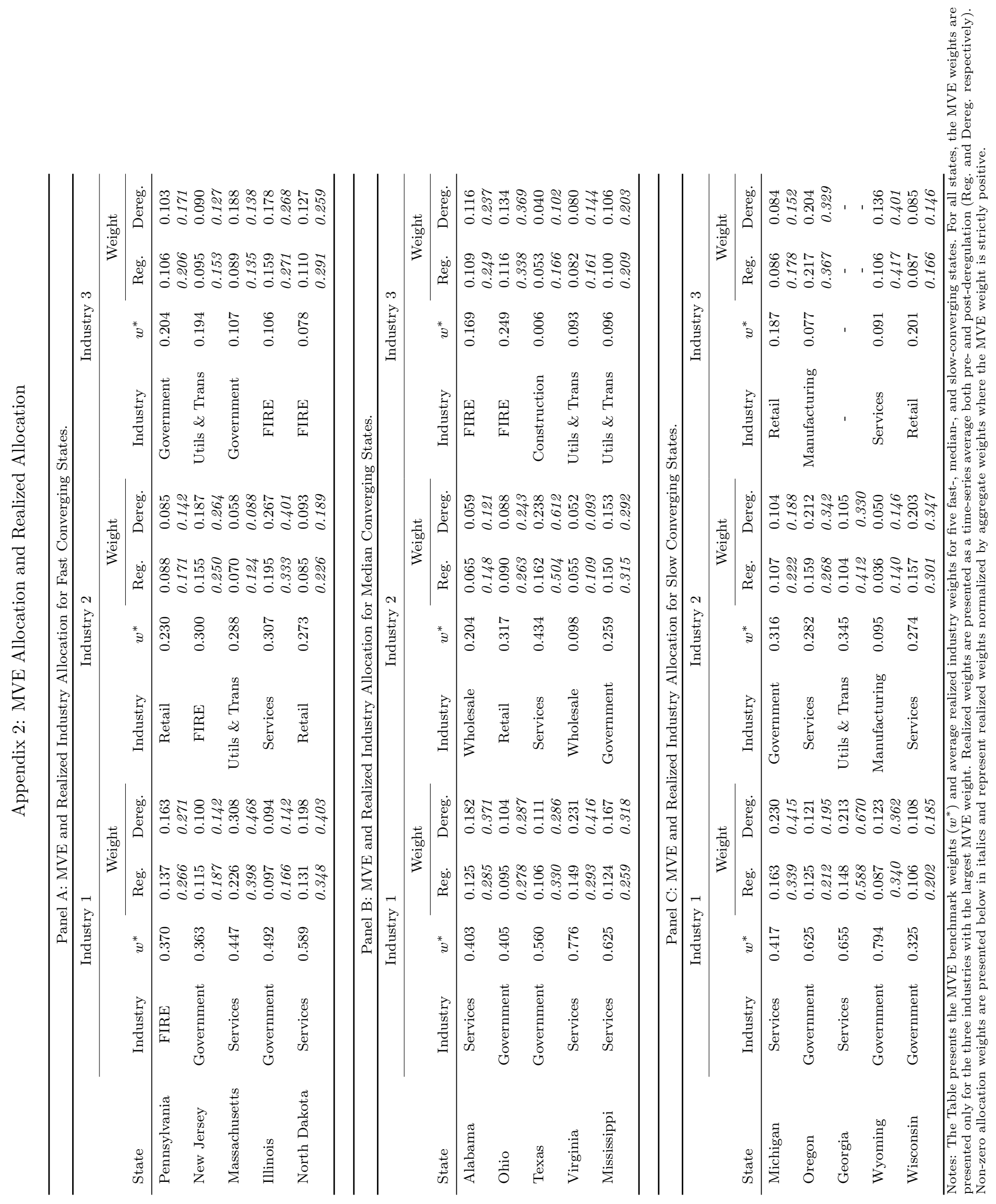




\section{References}

Acemoglu, Daron, and Fabrizio Zilibotti, 1997, Was Prometheus Unbound by Chance? Risk, Diversification and Growth, Journal of Political Economy 105, 709-751.

Arellano, Manuel, and Stephen Bond, 1991, Some Tests of Specification for Panel Data: Monte Carlo Evidence and an Application to Employment Equations, Review of Economic Studies 58, 277-97.

Ayhan Kose, Christopher Otrok, and Charles Whiteman, 2003, International Business Cycles: World, Region and Country Specific Factors, American Economic Review 93, 1216-1239.

Beck, Thorsten, Asli Demirguc-Kunt, Luc Laeven, and Ross Levine, Forthcoming 2008, Finance, Firm Size and Growth, Journal of Money, Credit, and Banking.

Beck, Thorsten, Ross Levine, and Norman Loayza, 2000, Finance and the Sources of Growth, Journal of Financial Economics 58, 261-300.

Bekaert, Geert, Campbell R. Harvey, Christian Lundblad, and Stephan Siegel, 2007, Global Growth Opportunities and Market Integration, Journal of Finance 62, 1081-1137.

Bertrand, Marianne, Esther Duflo, and Sendhil Mullainathan, 2004, How Much Should We Trust Differences-in-Differences Estimates?, Quarterly Journal of Economics 119, 249-75.

Bertrand, Marianne, Antoinette Schoar, and David Thesmar, 2007, Banking Deregulation and Industry Structure: Evidence from the 1985 French Banking Act, Journal of Finance $62,597-628$.

Black, Fischer, Blackwell, Business Cycles and Equilibrium. (Cambridge, MA).

Black, Sandra E., and Philip E. Strahan, 2005, Entrepreneurship and Bank Credit Availability, Journal of Finance 57.

Blundell, Richard, and Stephen Bond, 1998, Initial Conditions and Moment Restrictions in Dynamic Panel Data Models, Journal of Econometrics 87, 115-143.

Chari, Anusha, and Peter B. Henry, 2002, Capital Account Liberalization: Allocative Efficiency or Animal Spirits?, Stanford GSB Research Paper No. 1737.

Costello, Donna, 1993, A Cross-Country, Cross-Industry Comparison of Productivity Growth, Journal of Political Economy 101, 207-222.

Demirguc-Kunt, Asli, and Ross Levine, December 2001, Financial Structure and Economic Growth: A Cross-Country Comparison of Banks, Markets, and Development. (Cambridge, MA: MIT Press).

Demyanyk, Yuliya, Charlotte Ostergaard, and Bent E. Sorensen, 2007, U.S. Banking Deregulation, Small Businesses, and Interstate Insurance of Personal Income, Journal of Finance $62,2763-2801$. 
Dyck, Alexander, and Luigi Zingales, 2004, Private Benefits of Control: An International Comparison, Journal of Finance 59, 533-596.

Fisman, Raymond, and Inessa Love, 2004, Financial Development and Intersectoral Allocation: A New Approach, Journal of Finance 59.

Forni, Mario, and Lucrezia Reichlin, 1998, Let's Get Real: a Factor Analytical Approach to Disaggregated Business Cycle Dynamics., Review of Economic Studies 65, 453-473.

Huang, Rocco, Forthcoming 2008, The Real Effect of Bank Branching Deregulation: Comparing Contiguous Counties Across U.S. State Borders, Journal of Financial Economics.

Im, Kyung So, M. Hashem Pesaran, and Yongcheol Shin, 2003, Testing for Unit Roots in Heterogeneous Panels., Journal of Econometrics 115, 53-74.

Jayaratne, Jith, and Philip E. Strahan, 1996, The Finance-Growth Nexus: Evidence from Bank Branching Deregulation, Quarterly Journal of Economics 111, 639-70.

Jayaratne, Jith, and Philip E. Strahan, 1998, Entry Restrictions, Industry Evolution and Dynamic Efficiency, Journal of Law and Economics 41, 239-74.

King, Robert G., and Ross Levine, 1993, Finance and Growth: Schumpeter Might Be Right., Quarterly Journal of Economics 153, 717-738.

Koren, Miklos, and Silvana Tenreyro, 2007, Volatility and Development, Quarterly Journal of Economics 122, 243-287.

Kroszner, Randall S., 2001, The Motivations Behind Banking Reform, Regulation pp. 36-41.

Kroszner, Randall S., and Philip E. Strahan, 1999, What Drives Regulation? Economics and Politics of the Relaxation of Bank Branching Restrictions, Quarterly Journal of Economics $114,1437-67$.

Larrain, Borja, 2006, Do Banks Affect the Level and Composition of Industrial Volatility?, Journal of Finance 61, 1897-1925.

Levin, Andrew, Chien-Fu Lin, and James Chu, 2002, Unit root in panel data: Asymptotic and finite-sample Properties, Journal of Econometrics 108, 1-24.

Levine, Ross, and Sara Zervos, 1996, Stock Market Development and Long Run Growth.", World Bank Economic Review.

Morgan, Donald P., Bertrand Rime, and Philip E. Strahan, 2004, Bank Integration and State Business Cycles, Quarterly Journal of Economics 119, 1555-85.

Obstfeld, Maurice, 1994, Risk-Taking, Global Diversification and Growth, American Economic Review 84, 1310-1329.

Raddatz, Claudio, 2006, Liquidty Needs and the Vulnerability to Financial Underdevelopment, Journal of Financial Economics 80, 677-722. 
Rajan, Raghuram, and Luigi Zingales, 1998, Financial Dependence and Growth, American Economic Review 88, 559-586.

Saint-Paul, Gilles, 1993, Productivity Growth and the Structure of the Business Cycle, European Economic Review 37, 861-883.

Stockman, Alan, 1988, Sectoral and National Aggregate Disturbances to Industrial Output in Seven European Countries, Journal of Monetary Economics 21, 387-409.

Strahan, Philip E., 2003, The Real Effects of U.S. Banking Deregulation, Federal Reserve Bank of St. Louis Review.

Wurgler, Jeffrey, 2000, Financial Markets and the Allocation of Capital, Journal of Financial Economics 58, 187-214. 
Table 1: Reallocation Effects

\begin{tabular}{lcc}
\hline & $X=\mu$ & $X=\sigma$ \\
\hline State Level & $0.2435(0.1093)$ & $-0.1642(0.0897)$ \\
$X_{s, t}=\alpha_{s}+\gamma_{t}+\beta D E R E G_{s, t}$ & {$[0.026]$} & {$[0.068]$} \\
\hline Observations & 1,173 & 918 \\
\hline Industry Level & $0.1405(0.0481)$ & $0.0102(0.1006)$ \\
$X_{s, i, t}=\alpha_{s}+\gamma_{i, t}+\beta D E R E G_{s t}$ & {$[0.005]$} & {$[0.920]$} \\
\hline Observations & 21,045 & 16,470 \\
\hline
\end{tabular}

Notes: The Table reports estimates of $\beta$ corresponding to different dependent variables X, using the two-step methodology described in Bertrand, Duflo and Mullainathan (2004). State level estimations account for heteroskedasticity using the Huber-White correction. Industry level estimations are clustered at the State level. $\sigma$ is computed on the basis of 6-year forward rolling window between $t$ and $t+5$. Returns regressions do not include a constant volatility regressions do. P-values are reported between brackets, standard errors between parentheses. 
Table 2: Summary Statistics

\begin{tabular}{|c|c|c|c|c|c|c|}
\hline & \multicolumn{3}{|c|}{ State Performance } & \multicolumn{3}{|c|}{ Industry Performance } \\
\hline \multicolumn{7}{|c|}{ Growth } \\
\hline & Average & Early & Late & Average & Min & Max \\
\hline \multirow[t]{2}{*}{ Before } & 8.128 & & 6.256 & 8.122 & $\mathbf{5 . 0 3 9} 5.693$ & 12.204 \\
\hline & & & {$[\mathrm{WY}, 1988]$} & & {$[\mathbf{A G R}] \quad[\mathrm{MIN}]$} & [BUS] \\
\hline \multirow[t]{2}{*}{ After } & 6.916 & 8.210 & & 6.512 & $4.171 \quad \mathbf{3 . 6 1 4}$ & 10.288 \\
\hline & & {$[\mathrm{DE}, 1970]$} & & & {$[\mathrm{AGR}] \quad[\mathrm{MIN}]$} & [BUS] \\
\hline \multicolumn{7}{|c|}{ Volatility } \\
\hline & Average & Early & Late & Average & Min & Max \\
\hline \multirow[t]{2}{*}{ Before } & 5.264 & & 14.805 & 9.192 & $\mathbf{3 . 4 5 9} 4.162$ & $\mathbf{2 2 . 3 1 9} 21.402$ \\
\hline & & & {$[\mathrm{WY}, 1988]$} & & {$[$ HEL $] \quad[\mathrm{RET}]$} & {$[\mathbf{A G R}] \quad[\mathrm{MIN}]$} \\
\hline \multirow[t]{2}{*}{ After } & 3.273 & 2.857 & & 8.801 & $3.667 \quad \mathbf{3 . 4 7 9}$ & $16.079 \quad \mathbf{1 8 . 0 1 4}$ \\
\hline & & {$[\mathrm{DE}, 1970]$} & & & {$[\mathrm{HEL}] \quad[\mathbf{R E T}]$} & {$[\mathrm{AGR}] \quad[\mathrm{MIN}]$} \\
\hline
\end{tabular}

Notes: This excludes Government. Statistics before (after) are computed on non-deregulated (deregulated) years only. Numbers (sector names) in bold are the extrema referred to in the table headings. AZ denotes Arizona, DE Delaware. AGR: Agriculture, Farming and Fisheries, MIN: Mining, Oil, Gas and Non Metallic Minerals, BUS: Business Services and Other Services, HEL: Health, Educational, Legal, Social and Other Services, RET: Retail Trade. All numbers are in percent. Volatility is measured by the standard deviation of the growth rate. 
Table 3: Convergence to State Frontier

\begin{tabular}{|c|c|c|c|c|c|c|}
\hline \multicolumn{7}{|c|}{$X_{s, t+1}=\delta_{s}+\theta_{t}+\left(\alpha+\beta D E R E G_{s, t}\right) X_{s, t}+\gamma D E R E G_{s, t}+\epsilon_{s, t}$} \\
\hline \multicolumn{7}{|c|}{ i. Intrastate Deregulation } \\
\hline & \multicolumn{2}{|c|}{$X_{s, t}=D_{s, t}$} & \multicolumn{2}{|c|}{$X_{s, t}=\sigma_{s, t}-\sigma_{s}^{*}$} & \multicolumn{2}{|c|}{$X_{s, t}=\mu_{s, t}-\mu_{s}^{*}$} \\
\hline & OLS & GMM & OLS & GMM & OLS & GMM \\
\hline Interaction & $\begin{array}{c}-0.1018^{* * *} \\
(0.0389)\end{array}$ & $\begin{array}{c}-0.2437^{* * *} \\
(0.0356)\end{array}$ & $\begin{array}{c}-0.1285^{* * *} \\
(0.0298)\end{array}$ & $\begin{array}{c}-0.2081^{* * *} \\
(0.0277)\end{array}$ & $\begin{array}{l}-0.0041 \\
(0.0082)\end{array}$ & $\begin{array}{l}-0.0100 \\
(0.0085)\end{array}$ \\
\hline Lagged $X_{s, t}$ & $\begin{array}{c}0.6365^{* * *} \\
(0.0397)\end{array}$ & $\begin{array}{c}0.6820^{* * *} \\
(0.0402)\end{array}$ & $\begin{array}{c}0.7567^{* * *} \\
(0.0186)\end{array}$ & $\begin{array}{c}0.7784^{* * *} \\
(0.0343)\end{array}$ & $\begin{array}{c}0.8076^{* * *} \\
(0.0703)\end{array}$ & $\begin{array}{c}0.5715^{* * *} \\
(0.0293)\end{array}$ \\
\hline Deregulation & $\begin{array}{c}0.0039^{* * *} \\
(0.0010)\end{array}$ & $\begin{array}{c}0.0112^{* * *} \\
(0.0018)\end{array}$ & $\begin{array}{c}0.0021^{* *} \\
(0.0009)\end{array}$ & $\begin{array}{c}0.0059^{* * *} \\
(0.0010)\end{array}$ & $\begin{array}{c}-6.18 \times 10^{-05} \\
\left(2.06 \times 10^{-04}\right)\end{array}$ & $\begin{array}{c}-0.0002 \\
0.0002\end{array}$ \\
\hline Observations & 1,173 & 1,071 & 1,173 & 1,071 & 1,173 & 1,071 \\
\hline \multicolumn{7}{|c|}{ ii. Interstate Deregulation } \\
\hline & \multicolumn{2}{|c|}{$X_{s, t}=D_{s, t}$} & \multicolumn{2}{|c|}{$X_{s, t}=\sigma_{s, t}-\sigma_{s}^{*}$} & \multicolumn{2}{|c|}{$X_{s, t}=\mu_{s, t}-\mu_{s}^{*}$} \\
\hline & OLS & GMM & OLS & GMM & OLS & GMM \\
\hline Interaction & $\begin{array}{c}-0.1840^{* * *} \\
(0.0393)\end{array}$ & $\begin{array}{c}-0.2452^{* * *} \\
(0.0205)\end{array}$ & $\begin{array}{c}-0.2043^{* * *} \\
(0.0398)\end{array}$ & $\begin{array}{c}-0.2667^{* * *} \\
(0.0179)\end{array}$ & $\begin{array}{l}-0.0121 \\
(0.0104)\end{array}$ & $\begin{array}{c}0.0052 \\
(0.0054)\end{array}$ \\
\hline Lagged $X_{s, t}$ & $\begin{array}{c}0.6267^{* * *} \\
(0.0694)\end{array}$ & $\begin{array}{c}0.5426^{* * *} \\
(0.0300)\end{array}$ & $\begin{array}{c}0.7311^{* * *} \\
(0.0199)\end{array}$ & $\begin{array}{c}0.5904^{* * *} \\
(0.0281)\end{array}$ & $\begin{array}{c}0.7925^{* * *} \\
(0.0628)\end{array}$ & $\begin{array}{c}0.5619^{* * *} \\
(0.0286)\end{array}$ \\
\hline Deregulation & $\begin{array}{c}0.0065^{* * *} \\
(0.0020)\end{array}$ & $\begin{array}{c}0.0096^{* * *} \\
(0.0011)\end{array}$ & $\begin{array}{c}0.0037^{* * *} \\
(0.0013)\end{array}$ & $\begin{array}{c}0.0057^{* * *} \\
(0.0008)\end{array}$ & $\begin{array}{c}8.75 \times 10^{-05} \\
(0.0001)\end{array}$ & $\begin{array}{l}-0.0002 \\
(0.0002)\end{array}$ \\
\hline Observations & 1,173 & 1,071 & 1,173 & 1,071 & 1,173 & 1,071 \\
\hline
\end{tabular}

Notes: All estimations include a state-specific intercept and year effects. GMM implements the Aranello-Bond estimator to account for the presence of a lagged dependent variable in a dynamic panel model. Standard errors are clustered by State and reported between parentheses. *** (**, *) denote significance at the $1 \%(5 \%, 10 \%)$ confidence level. 
Table 4: Convergence in Allocation

\begin{tabular}{lcc}
\hline \multicolumn{2}{c}{$w_{s, i, t+1}-w_{s, i}^{*}=\delta_{s, i}+\theta_{t}+\left(\alpha+\beta D E R E G_{s, t}\right)\left[w_{s, i, t}-w_{s, i}^{*}\right]+\gamma D E R E G_{s, t}+\epsilon_{s, i, t}$} \\
\hline i. Intrastate Deregulation & All Weights & Non-Zero Weights \\
\hline Interaction & $-0.0064^{* *}$ & $-0.0055^{* *}$ \\
& $(0.0025)$ & $(0.0026)$ \\
{$\left[w_{s, i, t}-w_{s, i}^{*}\right]$} & $0.8884^{* * *}$ & $0.9286^{* * *}$ \\
& $(0.0299)$ & $(0.0100)$ \\
Deregulation & $-1.33 \times 10^{-05}$ & $2.56 \times 10^{-06}$ \\
& $\left(1.44 \times 10^{-04}\right)$ & $\left(7.18 \times 10^{-06}\right)$ \\
\hline Observations & 20,631 & 8,257 \\
\hline ii. Interstate Deregulation & & -0.0029 \\
\hline Interaction & $-0.0071^{* *}$ & $(0.0023)$ \\
& $(0.0027)$ & $0.9271^{* * *}$ \\
{$\left[w_{s, i, t}-w_{s, i}^{*}\right]$} & $0.8857^{* * *}$ & $(0.0100)$ \\
& $(0.0304)$ & $-4.06 \times 10^{-09}$ \\
Deregulation & $2.56 \times 10^{-06}$ & $\left(5.58 \times 10^{-09}\right)$ \\
\hline Observations & $\left(7.03 \times 10^{-06}\right)$ & 8,257 \\
\hline
\end{tabular}

Notes: All estimations include a state-industry specific intercept and year effects. GMM implements the Aranello-Bond estimator to account for the presence of a lagged dependent variable in a dynamic panel model. Non-Zero Weights estimations are for only those sectors with non-zero efficient allocations. Standard errors are clustered by State and reported between parentheses. $* * *(* *, *)$ denote significance at the $1 \%(5 \%, 10 \%)$ confidence level. We drop Agricultural Services since weights sum to unity. 


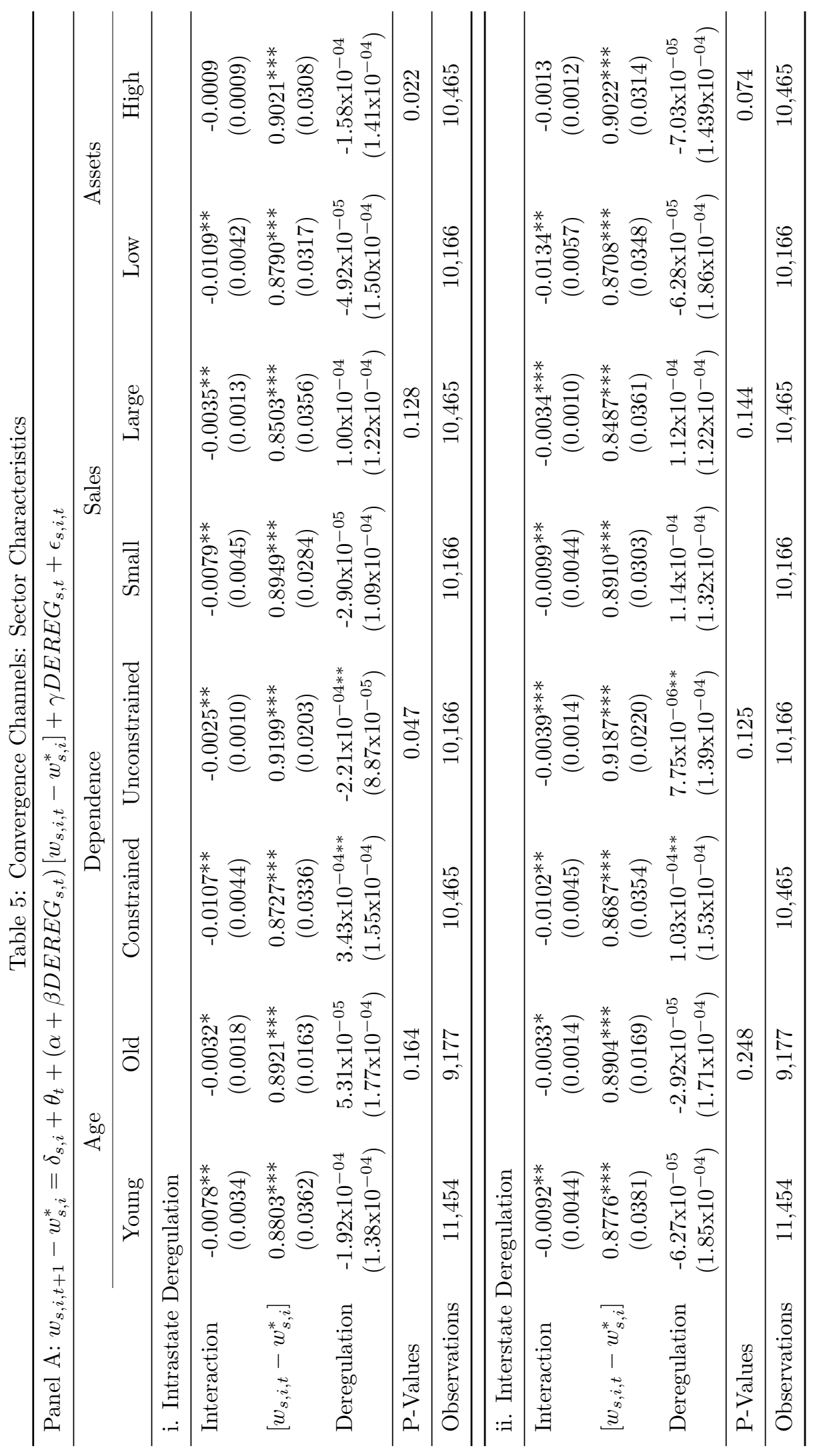




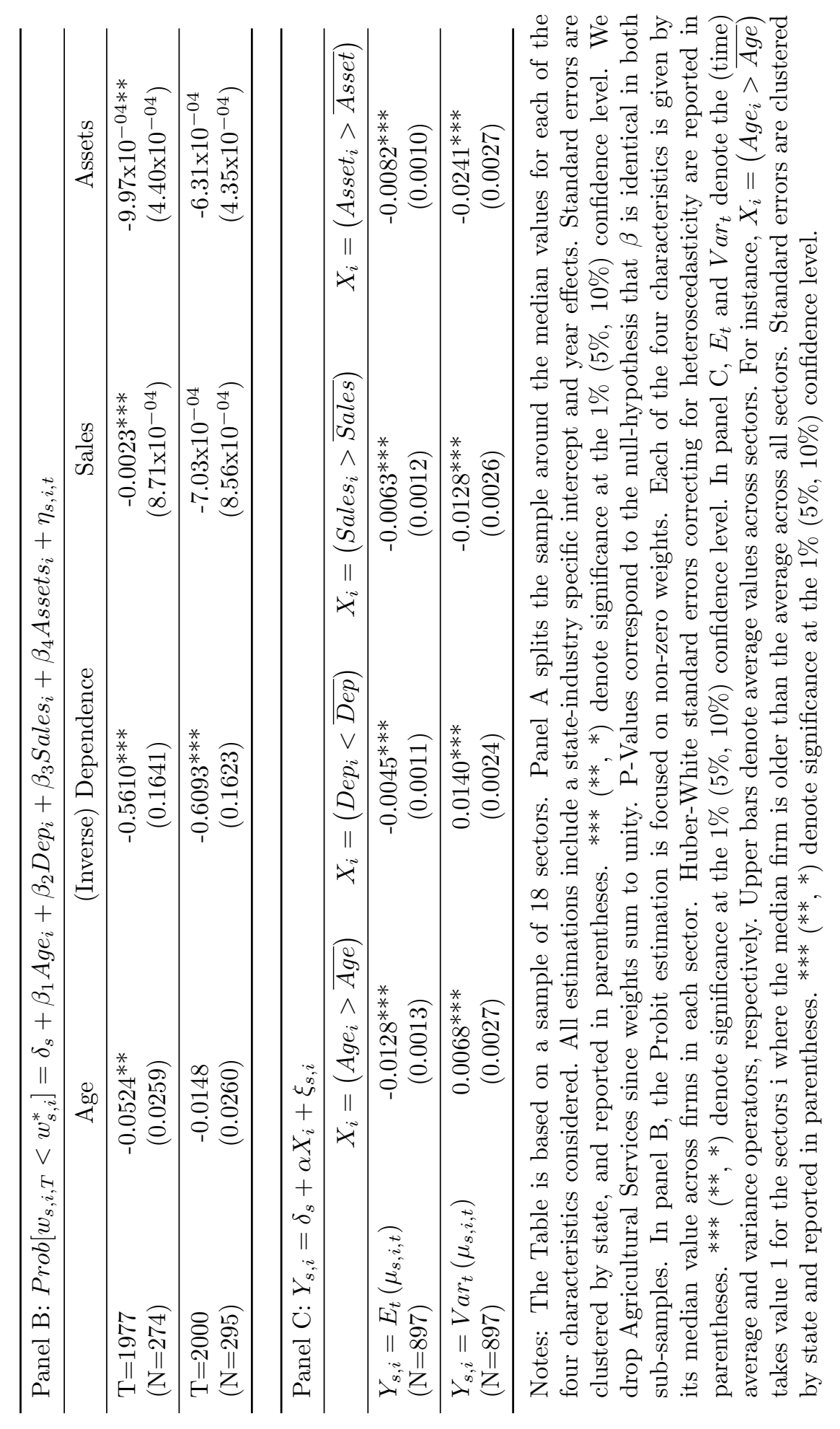


Table 6: Convergence Channels: State Characteristics

\begin{tabular}{|c|c|c|c|c|c|c|}
\hline \multicolumn{7}{|c|}{ Panel A: $D_{s, t+1}=\delta_{s}+\theta_{t}+\left(\alpha+\beta D E R E G_{s, t}\right) D_{s, t}+\gamma D E R E G_{s, t}+\epsilon_{s, t}$} \\
\hline \multicolumn{7}{|c|}{ i. Intrastate Deregulation } \\
\hline & \multicolumn{2}{|c|}{ Firm Age } & \multicolumn{2}{|c|}{ Firm Size } & \multicolumn{2}{|c|}{ State Area } \\
\hline & Young & Old & Small & Large & Big & Small \\
\hline Interaction & $\begin{array}{c}-0.0998^{* *} \\
(0.0422)\end{array}$ & $\begin{array}{c}-0.1385^{* *} \\
(0.0543)\end{array}$ & $\begin{array}{c}-0.1151^{* *} \\
(0.0423)\end{array}$ & $\begin{array}{l}-0.0512 \\
(0.0574)\end{array}$ & $\begin{array}{l}-0.0780 \\
(0.0500)\end{array}$ & $\begin{array}{c}-0.1668^{* *} \\
(0.0559)\end{array}$ \\
\hline Lagged $D_{s, t}$ & $\begin{array}{c}0.6402^{* * *} \\
(0.0419)\end{array}$ & $\begin{array}{c}0.6062^{* * *} \\
(0.0765)\end{array}$ & $\begin{array}{c}0.6499^{* * * *} \\
(0.0373)\end{array}$ & $\begin{array}{c}0.5368^{* * * *} \\
(0.1264)\end{array}$ & $\begin{array}{c}0.6127^{* * *} \\
(0.0400)\end{array}$ & $\begin{array}{c}0.6518^{* * *} \\
(0.0641)\end{array}$ \\
\hline Deregulation & $\begin{array}{c}0.0045^{* * *} \\
(0.0013)\end{array}$ & $\begin{array}{c}0.0044^{* *} \\
(0.0018)\end{array}$ & $\begin{array}{c}0.0057^{* * *} \\
(0.0013)\end{array}$ & $\begin{array}{c}0.0011^{* * *} \\
(0.0007)\end{array}$ & $\begin{array}{c}0.0041^{* *} \\
(0.0016)\end{array}$ & $\begin{array}{c}0.0054^{* *} \\
(0.0017)\end{array}$ \\
\hline P-Values & & 0.003 & & 0.000 & & 0.002 \\
\hline Observations & 575 & 598 & 598 & 575 & 598 & 575 \\
\hline \multicolumn{7}{|c|}{ ii. Interstate Deregulation } \\
\hline & \multicolumn{2}{|c|}{ Firm Age } & \multicolumn{2}{|c|}{ Firm Size } & \multicolumn{2}{|c|}{ State Area } \\
\hline & Young & Old & Small & Large & Big & Small \\
\hline Interaction & $\begin{array}{c}-0.2015^{* * *} \\
(0.0440)\end{array}$ & $\begin{array}{c}-0.1023^{* *} \\
(0.0449)\end{array}$ & $\begin{array}{c}-0.2242^{* * *} \\
(0.0412)\end{array}$ & $\begin{array}{c}-0.0961^{* * *} \\
(0.0230)\end{array}$ & $\begin{array}{c}-0.2109^{* * *} \\
(0.0493)\end{array}$ & $\begin{array}{c}-0.1086^{* *} \\
(0.0393)\end{array}$ \\
\hline Lagged $D_{s, t}$ & $\begin{array}{c}0.6362^{* * * *} \\
(0.0795)\end{array}$ & $\begin{array}{c}0.5963^{* * *} \\
(0.0777)\end{array}$ & $\begin{array}{c}0.6548^{* * * *} \\
(0.0730)\end{array}$ & $\begin{array}{c}0.5269^{* * * *} \\
(0.1117)\end{array}$ & $\begin{array}{c}0.6365^{* * *} \\
(0.0795)\end{array}$ & $\begin{array}{c}0.6261^{* * *} \\
(0.0670)\end{array}$ \\
\hline Deregulation & $\begin{array}{c}0.0081^{* * *} \\
(0.0029) \\
\end{array}$ & $\begin{array}{c}0.0029^{*} \\
(0.0015) \\
\end{array}$ & $\begin{array}{c}0.0090^{* * * *} \\
(0.0029) \\
\end{array}$ & $\begin{array}{c}0.0031^{* * *} \\
(0.0007) \\
\end{array}$ & $\begin{array}{c}0.0091^{* *} \\
(0.0033)\end{array}$ & $\begin{array}{c}0.0029^{* *} \\
(0.0001) \\
\end{array}$ \\
\hline P-Values & & 0.001 & & 0.000 & & 0.000 \\
\hline Observations & 575 & 598 & 598 & 575 & 598 & 575 \\
\hline
\end{tabular}




\begin{tabular}{|c|c|c|c|c|c|c|}
\hline \multicolumn{7}{|c|}{ Panel B: $w_{s, i, t+1}-w_{s, i}^{*}=\delta_{s, i}+\theta_{t}+\left(\alpha+\beta D E R E G_{s, t}\right)\left[w_{s, i, t}-w_{s, i}^{*}\right]+\gamma D E R E G_{s, t}+\epsilon_{s, i, t}$} \\
\hline & \multicolumn{2}{|c|}{ Firm Age } & \multicolumn{2}{|c|}{ Firm Size } & \multicolumn{2}{|c|}{ State Area } \\
\hline & Young & Old & Small & Large & Big & Small \\
\hline \multicolumn{7}{|c|}{ i. Intrastate Deregulation } \\
\hline Interaction & $\begin{array}{c}-0.0105^{* *} \\
(0.0042)\end{array}$ & $\begin{array}{l}-0.0024^{*} \\
(0.0013)\end{array}$ & $\begin{array}{c}-0.0102^{* * *} \\
(0.0036)\end{array}$ & $\begin{array}{l}-0.0015 \\
(0.0011)\end{array}$ & $\begin{array}{c}-0.0103^{* *} \\
(0.0041)\end{array}$ & $\begin{array}{c}-0.0031^{* * *} \\
(0.0011)\end{array}$ \\
\hline$\left[w_{s, i, t}-w_{s, i}^{*}\right]$ & $\begin{array}{c}0.8572^{* * *} \\
(0.0444)\end{array}$ & $\begin{array}{c}0.9270^{* * *} \\
(0.0143)\end{array}$ & $\begin{array}{c}0.8417^{* * *} \\
(0.0411)\end{array}$ & $\begin{array}{c}0.9417^{* * *} \\
(0.0098)\end{array}$ & $\begin{array}{c}0.8393^{* * *} \\
(0.0434)\end{array}$ & $\begin{array}{c}0.9422^{* * *} \\
(0.0111)\end{array}$ \\
\hline Deregulation & $\begin{array}{c}-2.04 \times 10^{-06} \\
\left(1.98 \times 10^{-05}\right)\end{array}$ & $\begin{array}{l}-1.75 \times 10^{-05} \\
\left(1.49 \times 10^{-05}\right)\end{array}$ & $\begin{array}{c}8.96 \times 10^{-07} \\
\left(1.21 \times 10^{-05}\right)\end{array}$ & $\begin{array}{l}-1.67 \times 10^{-05} \\
\left(1.62 \times 10^{-05}\right)\end{array}$ & $\begin{array}{c}-3.16 \times 10^{-06} \\
\left(1.35 \times 10^{-05}\right)\end{array}$ & $\begin{array}{c}-1.98 \times 10^{-05} \\
\left(1.82 \times 10^{-05}\right)\end{array}$ \\
\hline P-Values & & 0.005 & & 0.063 & & 0.033 \\
\hline Observations & 9,959 & 10,672 & 10,577 & 10,074 & 10,649 & 9,982 \\
\hline \multicolumn{7}{|c|}{ ii. Interstate Deregulation } \\
\hline Interaction & $\begin{array}{c}-0.01115^{* *} \\
(0.0047)\end{array}$ & $\begin{array}{c}-0.0041^{* *} \\
(0.0014)\end{array}$ & $\begin{array}{c}-0.0110^{* *} \\
(0.0042)\end{array}$ & $\begin{array}{c}-0.0030^{* * *} \\
(0.0009)\end{array}$ & $\begin{array}{c}-0.0098^{* *} \\
(0.0044)\end{array}$ & $\begin{array}{c}-0.0046^{* * *} \\
(0.0012)\end{array}$ \\
\hline$\left[w_{s, i, t}-w_{s, i}^{*}\right]$ & $\begin{array}{c}0.8518^{* * *} \\
(0.0468)\end{array}$ & $\begin{array}{c}0.9256^{* * *} \\
(0.0151)\end{array}$ & $\begin{array}{c}0.8379^{* * *} \\
(0.0428)\end{array}$ & $\begin{array}{c}0.9461^{* * *} \\
(0.0107)\end{array}$ & $\begin{array}{c}0.8371^{* * *} \\
(0.0452)\end{array}$ & $\begin{array}{c}0.9400^{* * *} \\
(0.0123)\end{array}$ \\
\hline Deregulation & $\begin{array}{c}1.02 \times 10^{-06} \\
\left(7.12 \times 10^{-06}\right)\end{array}$ & $\begin{array}{c}5.32 \times 10^{-06} \\
\left(1.28 \times 10^{-05}\right)\end{array}$ & $\begin{array}{c}7.43 \times 10^{-06} \\
\left(7.63 \times 10^{-06}\right)\end{array}$ & $\begin{array}{c}6.86 \times 10^{-06} \\
\left(1.37 \times 10^{-05}\right)\end{array}$ & $\begin{array}{c}3.29 \times 10^{-06} \\
\left(1.21 \times 10^{-05}\right)\end{array}$ & $\begin{array}{c}5.91 \times 10^{-06} \\
\left(6.70 \times 10^{-06}\right)\end{array}$ \\
\hline P-Values & & 0.004 & & 0.144 & & 0.447 \\
\hline Observations & 9,959 & 10,672 & 10,577 & 10,074 & 10,649 & 9,982 \\
\hline
\end{tabular}

Notes: Age and Size splits are based on the position of the representative firm in state s relative to the median across states. Representative firm age in state $\mathrm{s}$ is the industry-weighted average firm age in 1977. Representative firm size in state $\mathrm{s}$ is the 1977 share in overall state employment of firms with fewer than 20 employees. State areas are split around their median value across states. In panel A, all estimations include a state-specific intercept and year effects. In panel B, all estimations include a state-industry specific intercept and year effects. Standard errors are clustered by state, and reported between parentheses. ${ }^{* * *}(* *, *)$ denote significance at the $1 \%(5 \%, 10 \%)$ confidence level. P-Values correspond to the null-hypothesis that $\beta$ is identical in both sub-samples. 
Table 7: Stationarity Tests

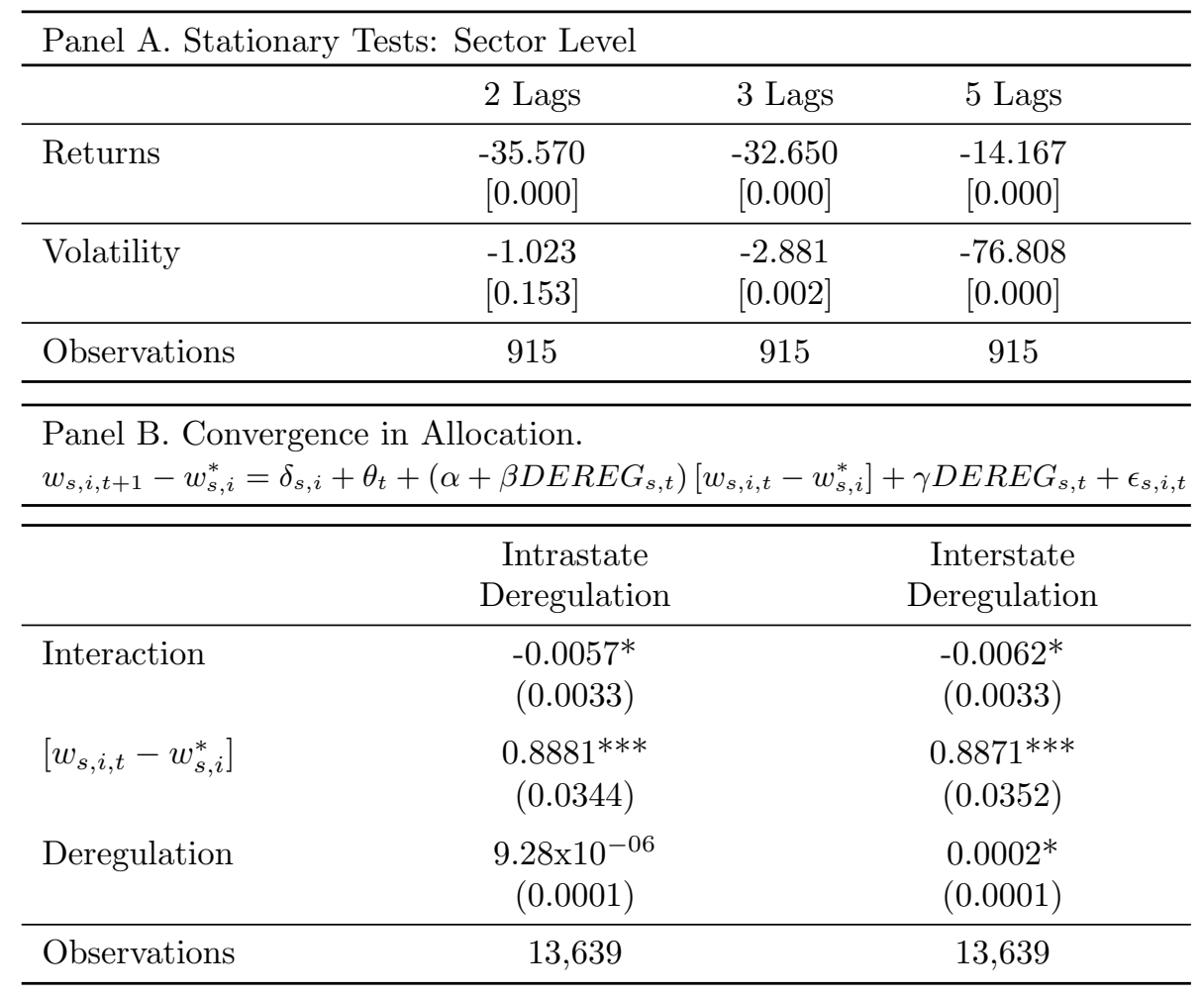

Notes: Panel A reports W-statistics for the Im-Pesaran-Shin (2003) test, distributed normally under the null hypothesis. P-values associated to the null hypothesis that all series are non-stationary are reported below. The estimation does not allow for any time trends, nor for any common time effects but it does allow for industry-state specific intercepts. All tests are performed on the residuals of a regression of the raw data on a binary variable taking value one after deregulation, i.e. controlling for structural breaks around the date. "Returns" uses the 23 years of yearly growth rates, "Volatility" corresponds to a 10-year moving average. Panel B reproduces estimates in the convergence of allocation in Table 4 for only those sectors in which we can strongly reject non-stationarity. We exclude all sectors with a $\mathrm{P}$-value (associated to the null hypothesis that all series are non-stationary) of less than 0.001 in the Levin, Lin and Chu (2002) test for non-stationarity. $* * *(* *, *)$ denote significance at the $1 \%(5 \%, 10 \%)$ confidence level. 
Table 8: Clean Frontier

\begin{tabular}{|c|c|c|c|}
\hline \multicolumn{4}{|c|}{ i. $X_{s, t+1}=\delta_{s}+\theta_{t}+\left(\alpha+\beta D E R E G_{s, t}\right) X_{s, t}+\gamma D E R E G_{s, t}+\epsilon_{s, t}$} \\
\hline & $X_{s, t}=D_{s, t}$ & $X_{s, t}=\sigma_{s, t}-\sigma^{*}$ & $X_{s, t}=\mu_{s, t}-\mu^{*}$ \\
\hline Interaction & $\begin{array}{c}-0.1122^{* *} \\
(0.0436)\end{array}$ & $\begin{array}{c}-0.0751^{* *} \\
(0.0343)\end{array}$ & $\begin{array}{c}-0.0114 \\
(0.0124)\end{array}$ \\
\hline Lagged $X_{s, t}$ & $\begin{array}{c}0.8043^{* * *} \\
(0.0467)\end{array}$ & $\begin{array}{c}0.7521^{* * *} \\
(0.0351)\end{array}$ & $\begin{array}{c}0.8181^{* * *} \\
(0.0665)\end{array}$ \\
\hline Deregulation & $\begin{array}{l}3.74 \times 10^{-03 *} \\
\left(2.10 \times 10^{-03}\right)\end{array}$ & $\begin{array}{l}2.28 \times 10^{-03 *} \\
\left(1.57 \times 10^{-03}\right)\end{array}$ & $\begin{array}{c}5.37 \times 10^{-04} \\
\left(4.34 \times 10^{-04}\right)\end{array}$ \\
\hline Observations & 368 & 368 & 368 \\
\hline \multicolumn{4}{|c|}{ ii. $w_{s, i, t+1}-w_{s, i}^{*}=\delta_{s, i}+\theta_{t}+\left(\alpha+\beta D E R E G_{s, t}\right)\left[w_{s, i, t}-w_{s, i}^{*}\right]+\gamma D E R E G_{s, t}+\epsilon_{s, i, t}$} \\
\hline & \multicolumn{2}{|c|}{ All Weights } & Non-Zero Weights \\
\hline Interaction & \multicolumn{2}{|c|}{$\begin{array}{c}-0.0162^{* *} \\
\left(8.26 \times 10^{-03}\right)\end{array}$} & $\begin{array}{c}-0.0107 \\
\left(7.26 \times 10^{-03}\right)\end{array}$ \\
\hline$\left[w_{s, i, t}-w_{s, i}^{*}\right]$ & \multicolumn{2}{|c|}{$\begin{array}{c}0.9125^{* * *} \\
(0.0589)\end{array}$} & $\begin{array}{c}0.9588^{* * *} \\
0.0219)\end{array}$ \\
\hline Deregulation & \multicolumn{2}{|c|}{$\begin{array}{l}-1.68 \times 10^{-07} \\
\left(3.11 \times 10^{-07}\right)\end{array}$} & $\begin{array}{l}-2.04 \times 10^{-07} \\
\left(4.21 \times 10^{-07}\right)\end{array}$ \\
\hline Observations & \multicolumn{2}{|c|}{3,680} & 3,680 \\
\hline
\end{tabular}

Notes: Table 8 reproduces key estimations using frontier estimates implied by fully deregulated state-years. All results pertain to a sample of 18 sectors, omitting Agricultural Services since they sum to unity. Estimations include a state-industry specific intercept and year effects. Standard errors are clustered by state, and are reported between parentheses. $* * *(* *, *)$ denote significance at the $1 \%(5 \%, 10 \%)$ confidence level. 
Table 9: Unconditional Convergence

\begin{tabular}{lccc}
\hline \multicolumn{4}{c}{$X_{s, u, t}=\delta_{s, u}+\theta_{t}+\rho X_{s, u, t-1}+\epsilon_{s, u, t}$} \\
\hline Lagged $X_{s, u, t}$ & $X_{s, u, t}=G a p_{s, u, t}$ & $X_{s, u, t}=G a p_{s, u, t}$ & $X_{s, u, t}=G a p_{s, u, t}^{*}$ \\
\hline Intercept & $0.8371^{* * *}$ & $0.9855^{* * *}$ & $0.9969^{* * *}$ \\
& $(0.0031)$ & $(0.0010)$ & $(0.0004)$ \\
Observations & $0.0644^{* * *}$ & $0.0096^{* * *}$ & -0.0003 \\
Year Effect & $(0.0014)$ & $(0.0008)$ & $(0.0008)$ \\
Country Pair Effect & 29,325 & 29,325 & 29,325 \\
\hline
\end{tabular}

Notes: The Table reports estimates of $\rho$ for different values of X. Gap $p_{s, u, t}=\Sigma_{i}\left|w_{s, i, t}-w_{u, i, t}\right|$ and $G a p_{s, u, t}^{*}=\Sigma_{i}\left|w_{s, i, t}-w_{u, i, t}\right|-\Sigma_{i}\left|w_{s, i}^{*}-w_{u, i}^{*}\right|$. Standard errors are reported between parentheses. $* * *(* *, *)$ denote significance at the $1 \%(5 \%, 10 \%)$ confidence level. 


\section{Figure 1. Convergence properties of distance to frontier for two fast-converging states \\ Pennsylvania}
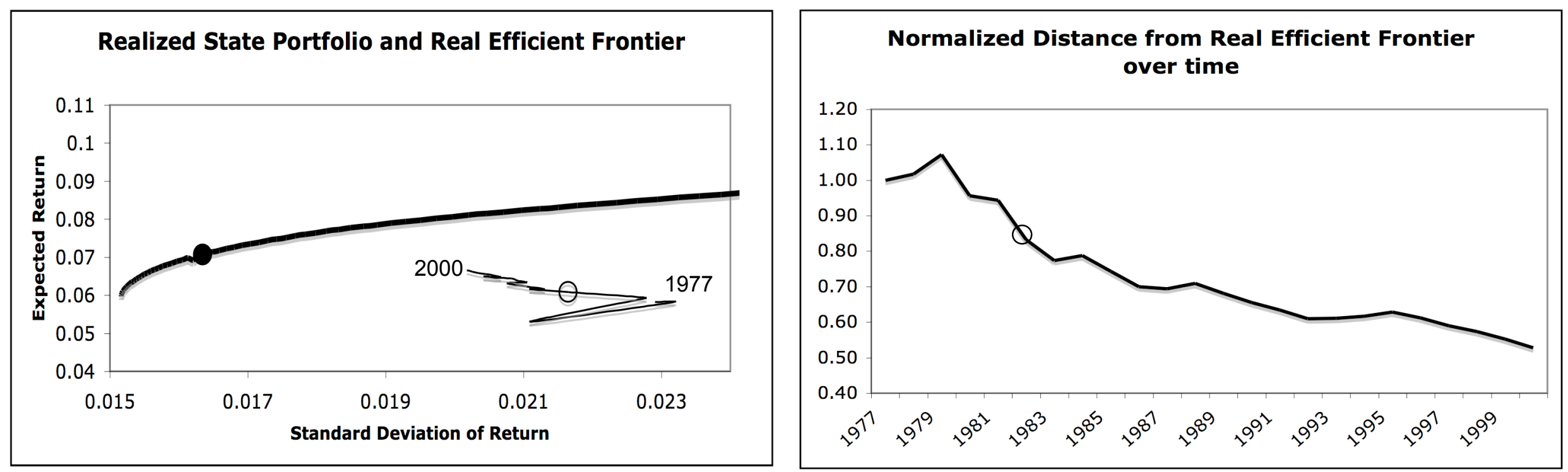

North Dakota
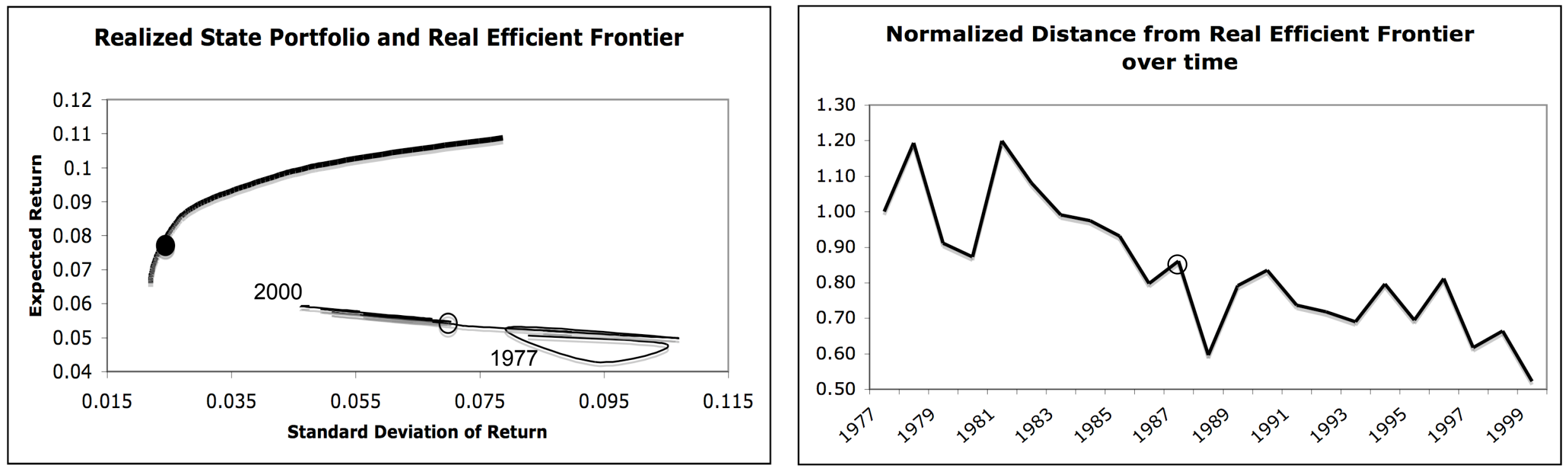

Key $\bigcirc$ Intrastate Deregulation 